\title{
Depolarization effect to enhance the performance of lithium ions
}

\section{batteries}

\author{
Jiaxin Zheng, ${ }^{1}$ Jun $\mathrm{Lu},{ }^{2}$ Khalil Amine, ${ }^{2 *}$ Feng Pan, ${ }^{1 *}$ \\ 1. School of Advanced Materials, Peking University, Peking University Shenzhen \\ Graduate School, Shenzhen 518055, China;
}

2. Chemical Sciences and Engineering Division, Argonne National Laboratory, Argonne, IL 60439;

Corresponding authors'E-mail: panfeng@pkusz.edu.cn (P.Fan)and amine@anl.gov (K. Amine)

\begin{abstract}
To meet the future challenges of energy storage, rechargeable lithium ions batteries (LIBs) have attracted great interest. Polarization of LIB electrodes and related active materials is a general problem for LIB applications during cycling, which leads to inhomogeneous environments for LIB electrodes and related active materials and degrades the performance of LIBs (e. g., capacity and voltage, rate capability, and capacity retention during electrochemical cycling). In this article, we offer a review of mechanisms of polarization and strategies of depolarization of LIB active cathode and anode materials and electrodes, including metal doping, nanostructure design, materials compositing, surface and interface engineering, and some other new technologies.
\end{abstract}


Keywords: Lithium ions batteries, electrode materials, polarization, depolarization

\section{Introduction}

Rechargeable lithium-ion batteries (LIBs) power most of today's portable electronics and are increasingly in demand for electrical vehicles and grid energy storage, due to the relatively high energy density, good cycle life, and good power performance of these batteries [1-3]. Though LIBs have attained great commercial success, there is still opportunity to improve their performance, for example, by understanding mechanism of the polarization and reducing the polarization (depolarization) in cathode and anode electrodes and related active materials during cycling, improving the thermal stability and safety, and reducing the cost. In particular, polarization, which leads to inhomogeneous environments for LIB electrodes and related active materials, is a general problem for LIB applications during cycling [4-7], especially in the active materials with poor electrical conductivity and Li-ion diffusivity, poor structural stability, and transition-metal cation dissolution, which degrades the performance (capacity, rate performance, and cycling stability) of batteries significantly. Thus, methods are being sought to understand mechanism of the polarization and to reduce the polarization effect in electrodes and related active materials in order to improve the battery performance.

At present, the methods being developed to reduce the polarization in electrode materials include use of carbon coatings [8], metal cation doping [4], device 
optimization [9], nanostructuring [10], materials compositing [11], surface and interface engineering[12], and morphology control [13]. As an example, nanostructure design is a widely employed and of particular importance for designing and fabricating nanostructured electrodes $[14,15]$. Nanocrystallites have received much attention as promising electrode materials for energy storage [16-18]. They benefit from the reduction of the Li-ion diffusion path length, which greatly decreases the polarization in electrode materials such as $\mathrm{LiMPO}_{4}(\mathrm{M}=\mathrm{Fe}, \mathrm{Mn}$, and Co) and allows increase of the charge/discharge rate, as well as reduces the electron diffusion length in such nonconductive materials. As another example of materials compositing, to reduce the polarization in anode materials, graphene is widely used in hybrid nanocomposites such as $\mathrm{Fe}_{3} \mathrm{O}_{4}$-graphene [19] and Si-graphene nanocomposite [20].

In this article, we review mechanisms to generate the polarization and strategies to induce the depolarization effect in electrode materials to enhance the performance of LIBs. We first describe the polarization phenomenon in electrode materials and the damage that it can cause to the battery performance. Then, the main technologies in enhancing depolarization are introduced: metal doping, nanostructure design, materials compositing, surface and interface engineering, and some other new technologies.

\section{Polarization in electrode materials}


Take the intercalation/deintercalation of $\mathrm{Li}$ ions into/from the cathode materials. This process involves (i) lithium-ion diffusion in the bulk of the cathode material, (ii) charge transfer reaction, (iii) lithium-ion diffusion through the electrode/electrolyte solid-liquid interface, and (iv) lithium-ion diffusion in the electrolyte [7]. Polarization would happen in every step: diffusion polarization in (i) and (iv), ohmic polarization in (ii), and activation polarization in (iii). The step with the slowest kinetics leads to the largest polarization, which would dominate the whole electrochemical performance and become rate determining.

The polarization effect is usually reflected in cyclic voltammograms (CVs), differential chronopotentiograms, and charge-discharge curves during electrochemical tests [7]. Fig. 1 present examples of the polarization effect for different cathode materials. One is $\mathrm{LiMn}_{1.5} \mathrm{Ni}_{0.5} \mathrm{O}_{4}$ [7], where a large difference in potential between the anodic and cathodic peaks can be observed in differential chronopotentiograms (Fig. 1a). This can be attributed to poor electronic conductivity and Li-ion diffusivity in the bulk cathode and Mn dissolution to form a thick solid-electrolyte interfacial (SEI) layer, which negatively affects the charge transfer and the Li-ion diffusion in the bulk and at the electrode/electrolyte interface.

The other cathode material is $45-\mathrm{nm} \mathrm{LiFePO}_{4}$ nanocrystals in organic electrolyte (1 $\mathrm{M} \mathrm{LiClO}_{4}$ electrolyte in a mixture of ethylene carbonate and dimethyl carbonate) [21], where a difference of around $0.5 \mathrm{~V}$ in potential is observed between the anodic and cathodic peaks in the CVs (Fig. 1b). This difference is attributed to the slow Li-ion 
transport across the electrode/electrolyte interface. The polarization effect would become more significant with increasing charge and discharge rate or after a greater numbers of cycles. Fig. 1c shows charge and discharge curves for $\mathrm{LiFePO}_{4}$ nanocrystals at various current densities in the organic electrolyte $\left(1 \mathrm{M} \mathrm{LiClO}_{4}\right.$ electrolyte in a mixture of ethylene carbonate and dimethyl carbonate). The curves indicate that with increasing current density, the polarization effect (voltage gap between the charge and discharge platform) becomes more serious. While cycling in aqueous electrolyte, the $45-\mathrm{nm} \mathrm{LiFePO}_{4}$ nanocrystals show a reduced polarization effect with much smaller difference in potential between the anodic and cathodic peaks (Fig. 1b), which was also shown in the charge and discharge curves (Fig. 1d).

Such polarization in electrode materials would slow the whole lithium insertion/extraction kinetics and degrade the battery performance in four ways. The first is that the rate performance would be reduced and thereby decrease the power density of batteries. The second is that the round-trip efficiency for energy conversion during the operation would be reduced, leading to more energy wasted. The third is that the cycling stability would be reduced, as the long-existing polarization would affect the structural stability of the cathode materials and the SEI layer. The fourth is that the polarization would prevent obtaining detailed electrochemical information in electrochemical tests (e.g., CVs), which makes it hard to clarify the cycling mechanisms (e.g., Li-ion diffusivity and the redox process for the transition metals) in batteries. 
Methods to reduce the polarization effect (or to enhance the depolarization effect) are focused on improving the kinetics in the above four processes during the intercalation/deintercalation of $\mathrm{Li}$ ions into/from the electrode materials. In the next sections, we discuss the main strategies employed to enhance the depolarization of electrode materials.

\section{Metal doping}

Fig. 1a also shows that after Fe substitution in $\mathrm{LiMn}_{1.5} \mathrm{Ni}_{0.5} \mathrm{O}_{4}$, the difference in potential between the anodic and cathodic peaks in $\mathrm{LiMn}_{1.5} \mathrm{Ni}_{0.34} \mathrm{Fe}_{0.16} \mathrm{O}_{4}$ becomes much smaller, which indicates a depolarization effect and can be attributed to the enhancement in electronic conductivity and the suppression of the Mn dissolution after Fe substitution [7].

The cathode material $\mathrm{LiFePO}_{4}$ was first recognized by John Goodenough [22] and was initially relegated to low-rate applications because of the slow kinetics associated with propagating a two-phase interface within an active particle. Nevertheless, due to its favorable electrochemical potential, low toxicity, low cost, and the abundance of iron, $\mathrm{LiFePO}_{4}$ has attracted great interest to determine the kinetics and develop ways to improve the rate performance. The recent studies on the electronic structure of $\mathrm{LiFePO}_{4}$ give critical insights on the transport mechanism inside $\mathrm{LiFePO}_{4}$ for further development of high-performance $\mathrm{LiFePO}_{4}$ cathodes. For a crystal material, the electronic structure is closely correlated with its crystal structure. In $\mathrm{LiFePO}_{4}$ crystal 
structure, $\left[\mathrm{FeO}_{6}\right]$ octahedrons are connected by sharing $\mathrm{O}$ corners to form a $2 \mathrm{D}$ network in $b c$ plane, and the $\left[\mathrm{PO}_{4}\right]$ tetrahedrons are physically separated by $\left[\mathrm{FeO}_{6}\right]$ octahedrons and act the joints to connect adjunct $\left[\mathrm{FeO}_{6}\right]$ planes. Therefore, the diffusion of electrons into and out of $\mathrm{LiFePO}_{4}$ has to rely on the $\left[\mathrm{FeO}_{6}\right] 2 \mathrm{D}$ framework through the electron transfer through the Fe-O bonds. Nevertheless, there are strong covalent bonds between $\mathrm{P}$ and $\mathrm{O}$ with a short bond length $(\sim 1.55 \AA)$, and the electron density along the Fe-O bonding direction is significantly lower than that in P-O bonding direction. Thus the Fe-O bonds have more ionic characteristics with a substantially longer bond length $(\sim 2.269 \AA)$. The localization electron density on $\mathrm{O}$ centers and Fe centers separately increases the energy barrier for electron hopping between $\mathrm{O}$ and $\mathrm{Fe}$, which is the active electrochemical center, leading to a low electronic conductivity. Thus, to improve the electronic conductivity of $\mathrm{LiFePO}_{4}$, we need to delocalize the electron density on $\mathrm{O}$ centers and Fe centers or introduce extra itinerate electrons into $\mathrm{LiFePO}_{4}$ by doping foreign elements. Chiang et al. demonstrated that controlled cation non-stoichiometry combined with solid-solution doping by metals supervalent to $\mathrm{Li}^{+}$increases the electronic conductivity of $\mathrm{LiFePO}_{4}$ by a factor of $\sim 10^{8}$, resulting in materials capable of being charged/discharged with an extremely high current up to $20 \mathrm{C}$, alternatively to complete charge/discharge the battery in less than 3 minutes[4]. Using first principles calculations, Shi et al. reported that the electronic conductivity of $\mathrm{LiFePO}_{4}$ can be enhanced by $\mathrm{Cr}$ doping at $\mathrm{Li}$ sites, which was further confirmed by their experiments: for $\mathrm{Li}_{1-3 \mathrm{x}} \mathrm{Cr}_{\mathrm{x}} \mathrm{FePO}_{4}$ with $\mathrm{x}=0.01$ 
and 0.03 , an enhancement of the electronic conductivity up to eight orders of magnitude comparing with pure $\mathrm{LiFePO}_{4}[23]$.

\section{Nanostructure design}

Rational design and manipulation of nanostructures, including the phase, size, and morphology, play crucial roles in enhancing the depolarization effect in electrode materials. Therefore, significant efforts have been devoted to phase- and morphology-controlled synthesis to explore novel properties and device performance.

\subsection{Nanostructured cathode materials}

$A b$ initio calculations predicted a fast diffusion coefficient for $\mathrm{Li}^{+}$in $1 \mathrm{D}$ channels along the $(010)$ direction in $\mathrm{LiFePO}_{4}[24,25]$, indicating the possibility to high rate applications (e.g., power tools, electrified vehicles, power grid). However, the occupation of $\mathrm{Fe}$ ions in lithium sites (anti-site defects), as commonly found in $\mathrm{LiFePO}_{4}$, can block the 1D diffusion channels and prevent $\mathrm{Li}^{+}$from hopping through the crystal structure. Moreover, Li-ion diffusion along the (001) direction is much slower, offering a sluggish way out to the blocked lithium and resulting in high lithium polarization and low rate capability [26]. Malik et al. reported that the reduction in the particle size of $\mathrm{LiFePO}_{4}$ to a critical value (below $50 \mathrm{~nm}$ ) can substantially reduce the amount of trapped lithium and reduce the effect of the sluggish (001) diffusion channel for full activation of the lithium in the cathode material [26]. As a result, decreasing the size of the $\mathrm{LiFePO}_{4}$ particles to the 
nanoscale has been widely employed to enable higher power density. Meanwhile, nanostructured $\mathrm{LiFePO}_{4}$ can also benefit from the reduction of the electron diffusion length. Many forms of nanostructured $\mathrm{LiFePO}_{4}$ (Fig. 2a-2c), such as nanoplates [13], nanorods [27], nanosheets [28], nanoparticles [21], and microspheres consisting of nanoplates or nanoparticles with an open 3D porous microstructure[29], have shown reduced polarization and high rate performance. All of them show a significant depolarization effect when used as cathode materials for LIBs (Fig. 2d), and the difference in potential between the anodic and cathodic peaks becomes much smaller. It should be noted that the depolarization effect also depends on the morphology of $\mathrm{LiFePO}_{4}$ nanocrystals. Designing $\mathrm{LiFePO}_{4}$ nanostructures with high ratio of (010) surface exposure would induce the most significant depolarization effect to improve the performance of $\mathrm{LiFePO}_{4} \mathrm{LIBs}[13,28]$.

Nanostructure design has also been applied to other cathode materials to enhance the depolarization effect. Wang et al. prepared $\mathrm{LiMn}_{1-\mathrm{x}} \mathrm{Fe}_{x} \mathrm{PO}_{4}$ nanorods on graphene (Fig. 2e) and realized a capacity of $65 \mathrm{mAh} \mathrm{g}^{-1}$ retained at $100 \mathrm{C}$ [30]. Sun et al. synthesized microscale and nanoporous $\mathrm{LiMn}_{0.85} \mathrm{Fe}_{0.15} \mathrm{PO}_{4}$ cathode material, which achieved high volumetric capacity[31]. The improved performance was attributed to the high tap density and the nanopores that, allowing electrolyte insertion through the particles, significantly reduce the Li-ion diffusion path. Okubo et al. reported that $\mathrm{LiCoO}_{2}$ nanocrystallites with mean sizes of $17 \mathrm{~nm}$ show a capacity of $75 \mathrm{mAh} \mathrm{g}^{-1}$ at a discharge rate of $100 \mathrm{C}$ [32]. Hosono et al. synthesized 50-100 nm $\mathrm{LiMn}_{2} \mathrm{O}_{4}$ 
nanowires (Fig. 2f), which achieved a capacity of $88 \mathrm{mAhg}^{-1}$ at a discharge rate of $135 \mathrm{C}$ [33]. In addition, $\mathrm{Li}_{2} \mathrm{FeSiO}_{4}$ is a newly developed cathode material with a large theoretical capacity of $332 \mathrm{mAh} \mathrm{g}^{-1}$. However, due to its poor electrical conductivity and large activation energies for Li-ion diffusion, this material shows a large polarization effect during cycling [34]. Nanostructured $\mathrm{Li}_{2} \mathrm{FeSiO}_{4}$ particles is also an efficient method to enhance the depolarization effect and thereby improve the electrochemical performance [35]. Yang et al. prepared d-hierarchical flower-like $\mathrm{Li}_{2} \mathrm{FeSiO}_{4}$ with secondary nanopetals (Fig. 2g) [36], which show a significant depolarization effect and exhibit a discharge capacity of $327.2 \mathrm{mAh} \mathrm{g}^{-1}$, approaching the full theoretical capacity with high-current and long-life performance.

Compared with the polarization effect in $\mathrm{LiFePO}_{4}, \mathrm{LiMn}_{2} \mathrm{O}_{4}$, and $\mathrm{Li}_{2} \mathrm{FeSiO}_{4}$, this effect in layered $\mathrm{Li}\left(\mathrm{Ni}_{\mathrm{x}} \mathrm{Mn}_{\mathrm{y}} \mathrm{Co}_{\mathrm{z}}\right) \mathrm{O}_{2}$ is usually induced by the chemical instability of the Ni-rich material, the structural transformation, and the $\mathrm{Ni} / \mathrm{Li}$ mixing during the charge/discharge process. Sun et al. reported a core-shell nanostructure in which a manganese-rich shell protects the high-capacity nickel-rich core [37]. The manganese-rich phase has a lower reversible capacity but higher chemical stability toward non-aqueous electrolytes than the nickel-rich core. This protects the side reactions between the Ni-rich core and the non-aqueous electrolyte and thereby reduces the polarization effect. However, long-term cycling will result in core-shell separation due to the mismatch of the lattice parameters of the two materials. To eliminate the sudden concentration change between the core and the shell, 
full-concentration gradient cathode materials with a nanorod structure [38] have been developed [39]. In a typical full-concentration gradient cathode, the concentration of nickel continuously decreases from the center toward the outer surface, while the concentration of the protective shell (manganese or cobalt) increases (Fig. 2h). In a full cell configuration, this material can deliver a reversible specific capacity of more than $200 \mathrm{mAh} \mathrm{g}^{-1}$ and excellent capacity retention for 1000 cycles.

\subsection{Nanostructured anode materials}

Anode materials for LIBs can be categorized into three groups: (1) insertion/de-insertion materials [40], including graphite [41] and titania [42], (2) alloy/de-alloy materials [43], such as tin and silicon alloys, and (3) conversion materials [44], such as metal oxides, metal sulfides, metal fluorides, and metal phosphides.

Lithium titanite $\left(\mathrm{Li}_{4} \mathrm{Ti}_{5} \mathrm{O}_{12}, \mathrm{LTO}\right)$ spinel has proven to be an acceptable alternative to graphite as the anode material because of its outstanding safety characteristics [42]. Lithium ions diffuse into the LTO lattice and occupy the free octahedral sites. Such insertion/de-insertion causes no strain to the host and minimum volumetric change, a very attractive property in anode materials. Most important, unlike graphite, the LTO is inert to the organic electrolyte (due to a relatively high operating potential), with minimal irreversible capacity loss during cycling. Unfortunately, due to its unique crystal structure and large electronic bandgap (2-3 eV) [45], LTO is intrinsically limited by the low electronic and Li-ion conductivity $\left(3 \times 10^{-8} \mathrm{~S} \mathrm{~cm}^{-1}\right.$ and $1 \times 10^{-12}-$ 
$1 \times 10^{-13} \mathrm{~S} \mathrm{~cm}^{-1}$ at $300 \mathrm{~K}$, respectively). Using LTO nanostructures in anodes significantly reduces the Li-ion diffusion pathway within particles and also increases the exposed active electrode area to the electrolyte, both advantageous features to achieve depolarization and good operating performance. In recent years, many attempts have been made to design efficient nanostructures (i.e., nanowires [46, 47], nanoflowers [48], and mesoporous nest-like structures [49]) by adopting new synthetic methods or optimizing existing ones such as solvothermal synthesis [50], molten-salt synthesis [51], and microwave irradiation solid-state reaction [52]. These synthetic approaches are usually accompanied by multivalent ion doping to further increase the electronic conductivity of LTO. Nanostructure design also play a great role to decrease the polarization effect in other intercalation/deintercalation anode materials. For example, $\mathrm{Li}_{3} \mathrm{VO}_{4}$ has recently attracted much attention as a new insertion-type anode material for LIBs, due to the large capacity and low voltage[53]. However, similar to LTO, the poor electronic conductivity of $\mathrm{Li}_{3} \mathrm{VO}_{4}$ would definitely lead to a significant polarization effect in electrodes. Nanostructured $\mathrm{Li}_{3} \mathrm{VO}_{4}$ has been proved to show significant depolarization effect and greatly improved electrochemical performance[53, 54].

Silicon has drawn much attention as an anode material [43, 55-62], as it offers a theoretical capacity of $3572 \mathrm{mAh} \mathrm{g}^{-1}$, more than one order magnitude higher than that of graphite and LTO. Elemental Si reacts with Li via an alloy/de-alloy mechanism, forming binary Li-Si alloys. However, due to a volumetric change of more than $300 \%$ 
during lithium insertion and extraction, Si-based electrodes typically suffer from poor capacity retention and a rapid reversible capacity loss during cycling. This is because the repeated expansion/contraction in the anode structure leads to particle cracking, active material isolation, and an unstable SEI, which ultimately results in a slowed kinetics for electron transport and Li-ion insertion/extraction and thereby induces a large polarization effect. Rational design of a variety of nanostructured Si electrodes can provide more free space to accommodate the expansion and buffer the induced volume change during cycling [57], thus preventing the structures from cracking and reducing the polarization effect greatly. The efforts on designing nanostructured $\mathrm{Si}$ electrodes have gone through three generations, encompassing solid (e.g., nanowires [63], core-shell nanowires [64], and nanoparticles [65]), hollow (e.g., nanotubes [66] and nanospheres[67]), and clamped hollow nanostructures. These nanostructures are usually directly grown on planar current collectors by chemical vapor deposition, based on a liquid-solid-vapor mechanism. With good electronic contact between the Si nanostructures and the current collector and electrolyte, the reversible capacity of those devices has reached as high as $2000 \mathrm{mAh} \mathrm{g}^{-1}$, and the battery cycling stability has also been significantly improved. Additionally, to overcome the unstable SEI problem, nanoscale material designs have been extensively explored. For example, the Cui group reported a novel yolk-shell design for Si anode to show high capacity with long cycle life and high coulombic efficiency [68], since the well-defined void 
space allows the Si particles to expand freely without breaking the outer carbon shell, therefore stabilizing the SEI on the shell surface.

Nanostructure design is also applied to other conversion anode materials to enhance the depolarization effect. For example, because of the polarization effect, some metal oxide anode materials (e.g., $\mathrm{NiO}, \mathrm{CuO}, \mathrm{Fe}_{2} \mathrm{O}_{3}, \mathrm{Fe}_{3} \mathrm{O}_{4}$, and $\mathrm{SnO}_{2}$ ) during cycling undergo large volume expansion in charge/discharge processes and exhibit poor electronic conductivity. Similar to the $\mathrm{Si}$ anode, the large volume changes of these anode particles would break the SEI and make it re-grow at the solid-liquid interfaces during cycling, leading to slowed Li-ion diffusion and depletion of the $\mathrm{Li}$ ions and electrolyte solution. One strategy to accommodate the expansion and buffer the induced volume change during cycling and improve the SEI stability is to create nanohollow structures (e.g., nanotube, core-shell, or yoke-shell structures)[69, 70]. We recently synthesized a core-shell structure with graphene as the shell and nano-hollow $\gamma-\mathrm{Fe}_{2} \mathrm{O}_{3}$ as the core through a Kirkendall process at room temperature [71]. This anode material exhibits remarkable electrochemical performance: a high reversible capacity of 1095,833 , and $551 \mathrm{mAh} \mathrm{g}^{-1}$ at current rates of $0.1 \mathrm{C}, 1 \mathrm{C}$, and 2 $\mathrm{C}$, respectively.

\section{Materials compositing}

As the polarization effect in many electrode materials (e.g., $\mathrm{LiFePO}_{4}, \mathrm{Li}_{2} \mathrm{FeSiO}_{4}$, LTO, and $\mathrm{SnS}$ ) is induced by their poor electronic conductivity, mixing the active 
particles with conductive additives is a widely adopted method to reduce this effect. Carbon coating is the mostly commonly used method to improve the transport of electrons to the active particles, resulting in significant improvements in rate performance [8]. Some nanomaterials (e.g., graphene and carbon nanotube) are used as conductive additives mixed with electrode active particles to form nanocomposite electrode materials, which enhance the depolarization effect.

Graphene nano-sheets, that is, sheets of a honeycomb carbon lattice that are one to five layers thick, exhibit high conductivity, light weight, high mechanical strength, structural flexibility, and large surface area [72, 73]. Graphene has been widely used in hybrid nanocomposites as the conductive matrix for electrode materials, such as $\mathrm{LiMn}_{(1-\mathrm{x})} \mathrm{Fe}_{\mathrm{x}} \mathrm{PO}_{4}$-graphene [30], $\mathrm{Li}_{2} \mathrm{FeSiO}_{4}$-graphene [35], $\mathrm{Fe}_{3} \mathrm{O}_{4}$-graphene (Fig. 3a) [19], and Si-graphene composites [20]. These nanocomposites offer several advantages. Firstly, the ultrathin graphene sheets can act as a barrier to prevent the aggregation of nanoparticles and enhance the cycle performance. Secondly, the porous graphene sheets can provide void space against the volume changes of the particles during lithium-ion insertion/extraction, which can improve the cycling performance. Thirdly, the graphene sheets themselves are active materials for additional $\mathrm{Li}^{+}$storage, which is of great benefit to the reversible specific capacity (3-5 layers provide a capacity of about $450 \mathrm{mAh} \mathrm{g}^{-1}$ ). Finally, the nanoparticles anchored on the surface of the graphene sheets can lead to a high rate performance due to the high electronic conductivity of the graphene sheets and the short path length for $\mathrm{Li}^{+}$ 
transport of the nanoparticles. Therefore, it is believed that anode nanocomposites with graphene possess reduced the polarization effect, resulting in improved reversible specific capacity, long cycling life, and good rate capability.

Carbon nanotubes (CNTs) have been usually mixed with active anode or cathode materials to enhance the electron transport kinetics, capacity utilization, and rate performance [74]. At present, the free-standing, binder-free, 3D-carbon nanotube networks prepared by filtration or deposition are considered as the ideal depolarizing structure [75-77]. Although carbon nanotube networks have also been used previously with layered cathode materials for the purpose of improving the electronic conductivity, the focus was only on improving the rate performance in these efforts [78, 79]. Interestingly, functionalized CNTs have been reported to show extra capacity as a cathode material [80]. We reported a strong enhancement in capacity for $\mathrm{Li}\left(\mathrm{Ni}_{0.5} \mathrm{Co}_{0.2} \mathrm{Mn}_{0.3}\right) \mathrm{O}_{2}$ (NCM523) through a novel design concept of interweaving it with single-wall CNTs (Fig. 3b) [11]. We found that the NCM523 and CNT contribute reversible capacity of $250 \mathrm{mAh} / \mathrm{g}$ and $50 \mathrm{mAh} / \mathrm{g}$, respectively, over the voltage range 3.0-4.8 V, along with long-term charge/discharge stability in the presence of a high voltage electrolyte. The observed performance improvements stem from the much reduced polarization in the electrode through the CNT network system. Additionally, we showed that the improved conductivity and reduced polarization of the electrode provide unique opportunities for in-depth studies of the cycling mechanism in cathode materials. Our NCM523/CNT electrodes exhibit 
well-defined two-stage delithiation kinetics, which is consistent with first-principle calculations. These technical advances and fundamental analysis cast new insights into electrode design and provide improved understanding of the charge and mass transport mechanism.

More complex hierarchical structures made of $\mathrm{Si}-\mathrm{C}$ composites have also been reported [81], where $\mathrm{Si}$ nanoparticles are uniformly deposited on carbon black dendritic backbones. In such architecture, both the Si and graphitic carbon are active components, where the carbon plays multiple roles: as a conductive matrix for more efficient charge transfer, as a buffer to accommodate the Si volume change, and as an active $\mathrm{Li}$ ion host for improved reversible capacity. These composites can reach a reversible capacity of $1950 \mathrm{mAh} \mathrm{g}^{-1}$ [82]. Wet-chemistry synthesis of Si-C nanocomposites provides a low-cost alternative for industrial production [83, 84]. To this end, hydro/solvothermal preparation of $\mathrm{Si}-\mathrm{C}$ nanostructures has been actively pursued, as well as supercritical-fluid-liquid growth for Si nanowires [84]. By coating Si nanowires with carbon, an overall reversible capacity of $1500 \mathrm{mAh} \mathrm{g}^{-1}$ was achieved. Finally, processing LTO paste with conductive nanomaterials has resolved the low conductivity issue. The conductive matrix accommodates individual LTO particles, which would otherwise be insulating, providing an efficient electron-transfer pathway [85].

\section{Surface and interface engineering}


Previous studies also reported that for some electrode materials, the rate-limiting step will be the interfacial reaction rather than the bulk transport for sufficiently small particle sizes [24, 86-88], and the Li intercalation rate within the nanoparticles is no longer the limiting step. The slowed kinetics can be attributed to the slow Li-ion transport across the electrode/electrolyte solid-liquid interface, the slow charge transfer at the electrode surface, and the surface structure transformation and decomposition induced by the side reactions with electrolyte, which lead to a significant polarization effect in the charge and discharge. To resolve such slowed kinetics of electrons and Li-ion transport at the electrode surface or interface, methods of surface and interface engineering have been extensively developed.

\subsection{Surface coatings}

This technology is applied to reduce the polarization effect for the following purposes: (i) to enhance the efficiency of electron injection/removal and the Li-ion transport at the surface; (ii) to protect the surface of electrode materials from dissolution; and (iii) to prevent side reactions at the electrode/electrolyte interface and protect the structural stability of the electrode surface.

As one example for the first purpose, nanocoating $\mathrm{LiFePO}_{4}$ with an electronic conductive medium (e.g., carbon [89], conductive polymer [90], or conductive metal phosphides [91]) and ionically conductive medium (e.g., $\mathrm{Li}_{3} \mathrm{PO}_{4}$ and $\mathrm{Li}_{4} \mathrm{P}_{2} \mathrm{O}_{7}[92,93]$ ) has proved to be beneficial for the depolarization effect. Surface coating also facilitates the interfacial charge transfer between the LTO and the electrolyte, 
enhancing the battery power density. The coating materials reported for the LTO include $\mathrm{Ag}, \mathrm{Cu}, \mathrm{C}, \mathrm{SnO}_{2}$, and conductive organic compounds [85].

With regard to the second purpose, for lithium manganese oxide spinel cathodes, $\mathrm{Mn}^{2+}$ dissolves into non-aqueous electrolyte and eventually deposits on the surface of the graphitic anode and degrades the electrochemical performance [94] [95]. Nanocoatings with 10-20-nm-thick layers of various oxides or fluorides, such as $\mathrm{ZrO}_{2}$ [96, 97], $\mathrm{TiO}_{2}$ [98], [99], $\mathrm{SiO}_{2}$ [97], $\mathrm{Al}_{2} \mathrm{O}_{3}$ [97], and $\mathrm{AlF}_{3}$ [100], have been shown to protect the $\mathrm{LiMn}_{2} \mathrm{O}_{4}$ cathode from dissolution. In addition, functional electrolyte additives that form a nano-passivation layer at the electrode surface during the initial formation have been found to significantly improve the cycle life [101, 102].

Unlike $\mathrm{LiCoO}_{2}$ and $\mathrm{LiMn}_{2} \mathrm{O}_{4}$, in which only 0.5 lithium atoms per transition metal atom can be reversibly removed and inserted, nickel-rich cathodes, $\mathrm{LiNi}_{1-\mathrm{x}-\mathrm{y}} \mathrm{Mn}_{\mathrm{x}} \mathrm{Co}_{\mathrm{y}} \mathrm{O}_{2}(\mathrm{x}, \mathrm{y}$, and $\mathrm{x}+\mathrm{y} \leq 0.5)$, can deliver a reversible capacity of about 200 $\mathrm{mAh} \mathrm{g}^{-1}$ (more than 0.7 lithium atoms per transition metal) [38]. Delithiated layered nickel-rich cathodes are extremely reactive due to a substantial overlap between the $3 \mathrm{~d}$ band of $\mathrm{Ni}$ and the $2 \mathrm{p}$ band of oxygen [103], leading to a chemical reaction between the charged nickel-rich layered cathode and the non-aqueous electrolyte. This reaction would lead to substantial reduction in reversible capacity (a loss of accessible lithium), a hike in the interfacial impedance (a loss of power density), and a severe reduction of the safety characteristics of the battery. Besides, nickel-rich oxides have a tendency to lose oxygen during cycling and form rock-salt $\mathrm{NiO}$ on the 
surface. All these lead to a growing polarization effect and degradation of the electrochemical performance during cycling [104]. Thus, as examples of the third purpose, various nanocoatings of oxides [105], fluorides [38], or phosphates [106] serve well as a physical barrier between the layered cathode and the electrolyte, resulting in a significant depolarization effect and an extended cycle life. This type of coating is generally composed of nanoparticles, typically ranging from $5 \mathrm{~nm}$ to 20 $\mathrm{nm}$, that are formed in the liquid phase and deposited on the surface of the cathode material. These nanoparticles tend to aggregate, protecting some areas but leaving other areas uncoated [107]. To maximize protection, more nanoparticles can be deposited to form a complete coating layer [108], which can be as thick as $100 \mathrm{~nm}$. Our recent work reported on a Ni-rich layered cathode coated with $\mathrm{LiFePO}_{4}$ nanoparticles (Fig. 4a and 4b) [109], which shows an improved depolarization effect and cycling life. This can be attributed to the excellent structural stability of the $\mathrm{LiFePO}_{4}$ surface, which can prevent the side reactions between the charged nickel-rich layered cathode and the non-aqueous electrolyte and protect the structural stability of the cathode surface.

\subsection{Sub-nanometer coatings}

A method that prevents the side reactions at the electrode/electrolyte interface and protects the structural stability of the surface of electrode materials is atomic layer deposition (ALD), which can generate sub-nanometer coatings on the cathode surface [108]. Scott et al. reported that a coating of 3-5 ALD cycles with Ni-rich cathodes 
gives the best electrochemical performance [12]. However, forming a complete, conformal coating in 3-5 ALD cycles is a challenge because the surface of Ni-rich cathodes lacks acidic groups that make ALD deposition effective. We recently reported that cells with $\mathrm{LiNi}_{0.5} \mathrm{Mn}_{0.3} \mathrm{Co}_{0.2} \mathrm{O}_{2}$ (NMC532) electrodes coated with $\mathrm{Al}_{2} \mathrm{O}_{3}$ by ALD have a reduced polarization effect and much enhanced cycling stability (Fig. 4c-4e) [110]. The ultrathin $\mathrm{ALD} \mathrm{Al}_{2} \mathrm{O}_{3}$ film can reduce the interface resistance of lithium-ion diffusion and enhance the surface stability of NMC532 by retarding the reactions at NMC532/electrolyte interfaces, thereby preventing the formation of new microstructural rock-salt phase $\mathrm{NiO}$ around the NMC532 surface.

\subsection{Surface doping}

Surface doping can tune the surface states of electrode materials and improve the charge transfer kinetics and the charge/discharge performance, thus reducing the polarization effect. Park et al. reported that the under-coordinated $\mathrm{Fe}^{2+} / \mathrm{Fe}^{3+}$ redox couple at the surface of the $\mathrm{LiFePO}_{4}$ cathode has a high barrier for charge transfer, but it can be stabilized by surface nitrogen or sulfur adsorption (Fig. 5a) [111]. Surface doping can also stabilize the surface cations to prevent the dissolution of transition metal cations. Lu et al. reported a nanoscale surface-doping approach $\left(\mathrm{Ti}^{4+}\right.$ doping) that minimizes $\mathrm{Mn}$ dissolution from spinel $\mathrm{LiMn}_{2} \mathrm{O}_{4}$ to show an enhanced depolarization effect and improved electrochemical performance (Fig. 5b) [98]. This improvement is caused by two factors: stabilization of the surface crystal structure of 
lithium manganate through cationic doping while the bulk lithium manganate structure is maintained, and protection of bulk lithium manganate from electrolyte corrosion while ion and charge transport channels are maintained on the surface through the electrochemically active doping layer.

\subsection{Surface prelithiation}

We recently proposed a unique "prelithiation process", which brought the $\mathrm{Li}\left(\mathrm{Ni}_{\mathrm{x}} \mathrm{Mn}_{\mathrm{y}} \mathrm{CO}_{\mathrm{z}}\right) \mathrm{O}_{2}(\mathrm{NMC})$ cathode to low potential before regular cycling and led to an SEI that is normally formed only on anode surfaces $[112,113]$. The complete coverage of the cathode surface by a $\sim 40$-nm-thick interphase prevented $\mathrm{Mn}$ (II) dissolution and minimized the side reactions of $\mathrm{Ni}, \mathrm{Co}$, and $\mathrm{Mn}$ at the SEI interface during the subsequent cycling. More important, such a "prelithiation" process activated a structure containing two $\mathrm{Li}$ layers near the surface of $\mathrm{Li}\left(\mathrm{Ni}_{\mathrm{x}} \mathrm{Mn}_{\mathrm{y}} \mathrm{Co}_{\mathrm{z}}\right) \mathrm{O}_{2}(\mathrm{x}$ $+\mathrm{y}+\mathrm{z}=1$ ) materials particles, as verified by $\mathrm{X}$-ray diffraction $(\mathrm{XRD})$ and first principle calculation. Hence, we generated a new cathode material with depolarized structure delivering both high capacity and excellent cycling performance.

\subsection{Electrode/electrolyte interface}

We recently reported a novel "Janus" hydrated interface in the $\mathrm{LiFePO}_{4}-\mathrm{H}_{2} \mathrm{O}$ system (Fig. 6a) [21], where the truncated symmetry of the solid $\mathrm{LiFePO}_{4}$ surface is compensated by chemisorbed $\mathrm{H}_{2} \mathrm{O}$ molecules, forming a half-solid $\left(\mathrm{LiFePO}_{4}\right)$ and half-liquid $\left(\mathrm{H}_{2} \mathrm{O}\right)$ amphiphilic coordination environment that eases the Li desolvation process near the surface (Fig. 6b). This, in turn, makes possible fast Li-ion transport 
across the solid/liquid interfaces and leads to an enhanced depolarization effect. As shown in Fig. 1b, when cycled in aqueous electrolyte, the 45-nm $\mathrm{LiFePO}_{4}$ nanocrystals show smaller difference in potential between the anodic and cathodic peaks in the CVs [21]. Accordingly, the charge-discharge curves for $\mathrm{LiFePO}_{4}$ nanocrystals in aqueous electrolyte show much less polarization effect with increasing current density (Fig. 1d).

\section{Other new technologies.}

\subsection{Disordering}

Traditionally, cathodes have been sought from well-ordered close-packed oxides, in particular layered rocksalt-type lithium transition-metal oxides (Li-TM-oxides) and ordered spinels, contrary to the limited attention to non-ordered materials[114]. In these ordered compounds, Li sites and pathways (a 2D slab in the layered oxides and a 3D network of tetrahedral sites in the spinels) are separated from the TM sublattice, which provides stability and electron storage capacity. Having well-ordered structures where there is little or no intermixing between the $\mathrm{Li}$ and the $\mathrm{TM}$ sublattice is generally considered important for obtaining high capacity cathode materials with good cycle life. In some cases, improvements in ordering have notably increased power or energy density. Previously, we reported that integrating some disordered structures into $\beta-\mathrm{LiFePO}_{4}$ can create new lithium migration passages, which allow lithium extraction/insertion from the structure, thus introducing a significant 
depolarization effect (Fig. 7a) [115]. The activation mechanism can be attributed to that the induced disorder (such as $\mathrm{Fe}_{\mathrm{Li}} \mathrm{Li}_{\mathrm{Fe}}$ antisite defects, crystal distortion, and amorphous domains) reduces the activation energies of Li-ion diffusion greatly and creates new lithium migration passages (Fig. 7a), which free the captive stored lithium atoms and facilitate their intercalation/deintercalation from the cathode. Ceder group found that cation disorder is not detrimental for layered materials, provided a sufficient amount $(\approx 20 \%)$ of excess lithium is present in the composition[116]. In fully cation-disordered materials, the lithium diffusion kinetics is enabled by $\approx 10 \%$ excess lithium. This is because excess lithium in the transition metal (TM) layer can create TM-0 Li-ion diffusion channels with low activation barriers due to the low repulsion between the activated Li-ion and disordered lithium/vacancies above it (Fig. 7b), thus to improve the Li-ion diffusivity significantly.

\subsection{Three-dimensional printing}

Lithium-ion transport to or from the active materials relies on Li-ion diffusion in the electrolyte more in a thicker porous electrode than a thinner one under the same conditions. This is because when LIBs are cycled under high rates, a larger concentration gradient of the electrolyte forms in the porous electrode. As the Li ions cannot pass through the porous electrode via bulk diffusion, the electrolyte diffusion and the electrode porosity would play a dominant role in the overall $\mathrm{Li}$-ion diffusion. Thus, the solution intrinsic diffusion coefficient, efficiency porosity, and electrode 
thickness could play a dominant role in the equivalent diffusion coefficient with the electrode beyond a certain thickness, which determines the whole kinetic process in LIBs at high rates[117]. The polarization effect under larger current densities for traditional electrodes can mainly be attributed to such factors.

Recently, three-dimensional (3D) printing technology has been developed to print 3D LIBs[117, 118], benefiting from its advantages of high areal energy density, short Li-ion transport distance, increased height of the interdigitated battery, and improved control of electrode width and thickness. Such 3D printed ultrathin porous electrodes with high efficiency porosity for LIBs can improve the Li-ion electrolyte diffusion and reduce the polarization of the Li-ion concentration in the electrolytes near the electrode surface during cycling, which usually exists in thick electrodes, leading to a significant depolarization effect and ultrahigh rate capability.

\section{Summary and outlook}

Polarization is a general problem in electrode materials during electrochemical cycling of LIBs, which slows the lithium insertion/extraction kinetics and degrades the battery performance. In this review, we have discussed the principal technologies that have been developed to enhance the depolarization effect in electrode materials. Table 1 shows a comparison of the performance of reported $\mathrm{LiFePO}_{4}$ LIBs after depolarization by different methods, including metal doping in bulk materials, 
nanostructure design, surface coating, surface doping, and electrode/electrolyte interface. We can see that all the methods take effect to introduce depolarization effect to improve the performance of $\mathrm{LiFePO}_{4} \mathrm{LIBs}$ greatly. We expect that the rational design of electrode materials will play a crucial role in the development of LIBs with high capacity, high rate performance, and long cycling life. However, the above technologies in batteries still need to be improved or further developed, and low-cost and large-scale compatible technologies should be developed to move the bench-scale demonstrations into practical industry-level applications:

- Metal doping. Metal doping is an effective method to improve the intrinsic electronic conductivity of cathode materials and can avoid the disadvantage of the reduced tap density by carbon coating. In the future, new doping elements and methods can be developed to further improve the performance of LIBs. For example, the previous pioneer works chose to dope Li sites in $\mathrm{LiFePO}_{4}$ with dopants that has an ionic radius in octahedral coordination smaller than that of $\mathrm{Fe}^{2+}$ (e. g., $\mathrm{Al}^{3+}, \mathrm{Cr}^{3+}, \mathrm{Ti}^{4+}, \mathrm{Zr}^{4+}, \mathrm{Nb}^{5+}$, and $\left.\mathrm{W}^{6+}\right)[4,23]$. Doping $\mathrm{Fe}$ sites in $\mathrm{LiFePO}_{4}$ with dopants that has an ionic radius in octahedral coordination larger than that of $\mathrm{Fe}^{2+}$ (e. g., $\left.\mathrm{Sn}^{2+}, \mathrm{Sn}^{4+}\right)$ may also take effect to improve the intrinsic electronic conductivity of $\mathrm{LiFePO}_{4}$. Furthermore, using high throughput computing method, we can calculate the doping cases in Li sites and Fe sites by all the elements in the periodic table and screen out the targeted dopants. Moreover, we can choose dopants that 
would act with dual or more functions in cathode materials. For example, our recent work shows that $\mathrm{Ti}$ substituting $\mathrm{Fe}$ sites in $\mathrm{Li}_{2} \mathrm{FeSiO}_{4}$ can not only introduce $n$-type doping to improve the electronic conductivity but also improve the structure stability and $\mathrm{Li}$-ion diffusion in $\mathrm{Li}_{2} \mathrm{FeSiO}_{4}[119]$.

- Nanotechnologies. Nanocrystallites have large specific surface area, which is expected to decrease the capacity for lithium storage because of the reduced binding energy for surface lithium with its truncated symmetry. Ceder et al. calculated the surface potential for lithium storage on a clean $\mathrm{LiFePO}_{4}(010)$ surface, which is the main exposed surface, and found that it is lower than the bulk value by $0.6 \mathrm{eV}$ [120]. Indeed, nanometer-sized LFP particles exhibit sloping voltage charge/discharge curves, unlike the charge/discharge voltage plateau seen in larger LFP particles [121]. Meanwhile, compared with bulk materials, the large specific surface area of nanocrystallites could lead to severe chemical activities due to the facilitated chemical catalysis [122], which typically compromises electrolyte stability and enhances the dissolution of transition-metal cations [123], which jeopardizes the stability and cycling life of the battery. Moreover, nanosizing is expected to reduce the tap density and further decrease the total energy density of an electrode[29, 31]. It is thus paramount to overcome these problems in order to make the nanocrystallite electrode truly useful and beneficial. One strategy to overcome the above problems is to develop surface reconstruction 
technologies, which can truly help to not only utilize the advantages of the nanocrystallites' fast Li-ion transport to achieve high power density, but also use the ultra-high surface area to store Li ions to enhance energy density and avoid side reactions with electrolytes for long-term stability. For example, the incorporation of LFP nanocrystals with few-layer graphene can deliver a capacity of $208 \mathrm{mAh} \mathrm{g}^{-1}$, which is beyond the theoretical capacity of LFP (170 $\left.\mathrm{mAh} \mathrm{g}^{-1}\right)[124]$. Compared with the same LFP particles coated with traditional thin amorphous carbon layer, the cycling life and rate performance are also improved.

- Surface and interface engineering. The surface and interface chemistry plays an important role on the whole kinetics of LIBs. The future surface engineering technologies should focus not only on improving the surface stability of electrode materials but also on the surface and interface kinetics (e.g., electrode/electrolyte interface), which is especially important for the electrode/solid electrolyte interface in all solid LIBs.

- Disordering is a new concept and technology developed recently, which can effectively reduce the depolarization effect. Ceder group have done much pioneer works in this field[114, 116]. There is much works that can be done in the future to further develop this strategy, including the mechanisms, the design principles and the methods to introduce appropriate cation disordering. 


\section{Acknowledgement}

The work was financially supported by National Materials Genome Project (2016YFB0700600) Guangdong Innovation Team Project (No. 2013N080), Shenzhen Science and Technology Research Grant (No. ZDSY20130331145131323, JCYJ20140903101633318, JCYJ2014090-3101617271). This work was also supported by the U.S. Department of Energy under Contract DE-AC0206CH11357 with the main support provided by the Vehicle Technologies Office, Department of Energy (DOE) Office of Energy Efficiency and Renewable Energy (EERE).

\section{References:}

[1] M. Armand, J.M. Tarascon, Nature, 451 (2008) 652-657.

[2] B. Dunn, H. Kamath, J.-M. Tarascon, Science, 334 (2011) 928-935.

[3] M.S. Whittingham, Chem. Rev., 104 (2004) 4271-4302.

[4] S.-Y. Chung, J.T. Bloking, Y.-M. Chiang, Nat. Mater., 1 (2002) 123-128.

[5] B.-L. He, B. Dong, H.-L. Li, Electrochem. Commun., 9 (2007) 425-430.

[6] M. Yonemura, A. Yamada, Y. Takei, N. Sonoyama, R. Kanno, J. Electrochem. Soc., 151 (2004) A1352-A1356.

[7] J. Liu, A. Manthiram, J. Phys. Chem. C, 113 (2009) 15073-15079.

[8] N. Ravet, Y. Chouinard, J.F. Magnan, S. Besner, M. Gauthier, M. Armand, J. Power Sources, 97-98 (2001) 503-507. 
[9] R. Malik, A. Abdellahi, G. Ceder, J. Electrochem. Soc., 160 (2013) A3179-A3197.

[10] P.G. Bruce, B. Scrosati, J.-M. Tarascon, Angew. Chem. Int. Ed., 47 (2008) 2930-2946.

[11] Z. Wu, X. Han, J. Zheng, Y. Wei, R. Qiao, F. Shen, J. Dai, L. Hu, K. Xu, Y. Lin, W. Yang, F. Pan, Nano Lett., 14 (2014) 4700-4706.

[12] I.D. Scott, Y.S. Jung, A.S. Cavanagh, Y. Yan, A.C. Dillon, S.M. George, S.-H. Lee, Nano Lett., 11 (2011) 414-418.

[13] L. Wang, X. He, W. Sun, J. Wang, Y. Li, S. Fan, Nano Lett., 12 (2012) $5632-5636$.

[14] L. Ji, Z. Lin, M. Alcoutlabi, X. Zhang, Energy Environ. Sci., 4 (2011) 2682-2699.

[15] Y. Wang, G. Cao, Adv. Mater., 20 (2008) 2251-2269.

[16] L. Ma, K.E. Hendrickson, S. Wei, L.A. Archer, Nano Today, 10 (2015) 315-338.

[17] Q.F. Zhang, E. Uchaker, S.L. Candelaria, G.Z. Cao, Chem. Soc. Rev., 42 (2013) 3127-3171.

[18] H. Wang, H. Dai, Chem. Soc. Rev., 42 (2013) 3088-3113.

[19] G. Zhou, D.-W. Wang, F. Li, L. Zhang, N. Li, Z.-S. Wu, L. Wen, G.Q. Lu, H.-M. Cheng, Chem. Mater., 22 (2010) 5306-5313. 
[20] J. Chang, X. Huang, G. Zhou, S. Cui, P.B. Hallac, J. Jiang, P.T. Hurley, J. Chen, Adv. Mater., 26 (2014) 758-764.

[21] J. Zheng, Y. Hou, Y. Duan, X. Song, Y. Wei, T. Liu, J. Hu, H. Guo, Z. Zhuo, L. Liu, Z. Chang, X. Wang, D. Zherebetskyy, Y. Fang, Y. Lin, K. Xu, L.-W. Wang, Y. Wu, F. Pan, Nano Lett., 15 (2015) 6102-6109.

[22] A.K. Padhi, K.S. Nanjundaswamy, J.B. Goodenough, J. Electrochem. Soc., 144 (1997) 1188-1194.

[23] S. Shi, L. Liu, C. Ouyang, D.-s. Wang, Z. Wang, L. Chen, X. Huang, Phys. Rev. B, 68 (2003) 195108.

[24] G.K.P. Dathar, D. Sheppard, K.J. Stevenson, G. Henkelman, Chem. Mater., 23 (2011) 4032-4037.

[25] D. Morgan, A. Van der Ven, G. Ceder, Electrochem. Solid-State Lett., 7 (2004) A30-A32.

[26] R. Malik, D. Burch, M. Bazant, G. Ceder, Nano Lett., 10 (2010) 4123-4127.

[27] H. Liu, H. Yang, J. Li, Electrochimica Acta, 55 (2010) 1626-1629.

[28] Y. Zhao, L. Peng, B. Liu, G. Yu, Nano Lett., 14 (2014) 2849-2853.

[29] C. Sun, S. Rajasekhara, J.B. Goodenough, F. Zhou, J. Am. Chem. Soc., 133 (2011) 2132-2135.

[30] H. Wang, Y. Yang, Y. Liang, L.-F. Cui, H. Sanchez Casalongue, Y. Li, G. Hong, Y. Cui, H. Dai, Angew. Chem. Int. Ed., 123 (2011) 7502-7506. 
[31] Y.K. Sun, S.M. Oh, H.K. Park, B. Scrosati, Adv. Mater., 23 (2011) $5050-5054$

[32] M. Okubo, E. Hosono, J. Kim, M. Enomoto, N. Kojima, T. Kudo, H. Zhou, I. Honma, J. Amer. Chem. Soc., 129 (2007) 7444-7452.

[33] E. Hosono, T. Kudo, I. Honma, H. Matsuda, H. Zhou, Nano Lett., 9 (2009) 1045-1051.

[34] R. Dominko, J. Power Sources, 184 (2008) 462-468.

[35] J. Yang, L. Hu, J. Zheng, D. He, L. Tian, S. Mu, F. Pan, J. Mater. Chem. A, 3 (2015) 9601-9608.

[36] J. Yang, X. Kang, D. He, A. Zheng, M. Pan, S. Mu, J. Mater. Chem. A, 3 (2015) 16567-16573.

[37] Y.-K. Sun, S.-T. Myung, M.-H. Kim, J. Prakash, K. Amine, J. Am. Chem. Soc., 127 (2005) 13411-13418.

[38] Y.-K. Sun, M.-J. Lee, C.S. Yoon, J. Hassoun, K. Amine, B. Scrosati, Adv. Mater., 24 (2012) 1192-1196.

[39] Y.K. Sun, Z.H. Chen, H.J. Noh, D.J. Lee, H.G. Jung, Y. Ren, S. Wang, C.S. Yoon, S.T. Myung, K. Amine, Nat. Mater., 11 (2012) 942-947.

[40] M. Winter, J.O. Besenhard, M.E. Spahr, P. Novák, Adv. Mater., 10 (1998) 725-763.

[41] J. Dahn, A. Sleigh, H. Shi, J. Reimers, B. Way, Q. Zhong, U. Von Sacken, Lithium batteries: new materials, developments, and perspectives, (1994). 
[42] T. Ohzuku, A. Ueda, N. Yamamoto, J. Electrochem. Soc., 142 (1995) $1431-1435$.

[43] C.-M. Park, J.-H. Kim, H. Kim, H.-J. Sohn, Chem. Soc. Rev., 39 (2010) 3115-3141.

[44] M. Reddy, G. Subba Rao, B. Chowdari, Chem. Rev., 113 (2013) 5364-5457.

[45] C.Y. Ouyang, Z.Y. Zhong, M.S. Lei, Electrochem. Commun, 9 (2007) $1107-1112$

[46] L. Shen, E. Uchaker, X. Zhang, G. Cao, Adv. Mater., 24 (2012) 6502-6506.

[47] Q. Zhang, Y. Guo, K. Guo, T. Zhai, H. Li, Chem. Commun., 52 (2016) $6229-6232$.

[48] H.-c. Chiu, G.P. Demopoulos, ECS Trans., 50 (2013) 119-126.

[49] J. Chen, L. Yang, S. Fang, S.-i. Hirano, K. Tachibana, J. Power Sources, 200 (2012) 59-66.

[50] A. Laumann, M. Bremholm, P. Hald, M. Holzapfel, K.T. Fehr, B.B. Iversen, J. Electrochem. Soc., 159 (2011) A166-A171.

[51] Y. Bai, F. Wang, F. Wu, C. Wu, L.-y. Bao, Electrochim. Acta, 54 (2008) 322-327.

[52] J. Li, Y.-L. Jin, X.-G. Zhang, H. Yang, Solid State Ion., 178 (2007) 1590-1594. 
[53] C. Liao, Q. Zhang, T. Zhai, H. Li, H. Zhou, Energy Storage Mater., 7 (2017) 17-31.

[54] G. Shao, L. Gan, Y. Ma, H. Li, T. Zhai, J. Mater. Chem. A, 3 (2015) $11253-11260$.

[55] B.A. Boukamp, G.C. Lesh, R.A. Huggins, J. Electrochem. Soc., 128 (1981) 725-729.

[56] M. Winter, J.O. Besenhard, Electrochim. Acta, 45 (1999) 31-50.

[57] H. Wu, Y. Cui, Nano Today, 7 (2012) 414-429.

[58] M. Yoshio, H. Wang, K. Fukuda, T. Umeno, N. Dimov, Z. Ogumi, J. Electrochem. Soc., 149 (2002) A1598-A1603.

[59] C.S. Johnson, N. Li, C. Lefief, M.M. Thackeray, Electrochem. Commun, 9 (2007) 787-795.

[60] M.N. Obrovac, L. Christensen, D.B. Le, J.R. Dahn, J. Electrochem. Soc., 154 (2007) A849-A855.

[61] I. Sandu, P. Moreau, D. Guyomard, T. Brousse, L. Roué, Solid State Ion., 178 (2007) 1297-1303.

[62] V.P. Phan, B. Pecquenard, F. Le Cras, Adv. Funct. Mater., 22 (2012) 2580-2584.

[63] C.K. Chan, H. Peng, G. Liu, K. Mcllwrath, X.F. Zhang, R.A. Huggins, Y. Cui, Nat. Nano., 3 (2008) 31-35. 
[64] R. Ruffo, S.S. Hong, C.K. Chan, R.A. Huggins, Y. Cui, J. Phys. Chem. C, 113 (2009) 11390-11398.

[65] T.H. Hwang, Y.M. Lee, B.-S. Kong, J.-S. Seo, J.W. Choi, Nano Lett., 12 (2012) 802-807.

[66] M.-H. Park, M.G. Kim, J. Joo, K. Kim, J. Kim, S. Ahn, Y. Cui, J. Cho, Nano Lett., 9 (2009) 3844-3847.

[67] Y. Yao, M.T. McDowell, I. Ryu, H. Wu, N. Liu, L. Hu, W.D. Nix, Y. Cui, Nano Lett., 11 (2011) 2949-2954.

[68] N. Liu, H. Wu, M.T. McDowell, Y. Yao, C. Wang, Y. Cui, Nano Lett., 12 (2012) 3315-3321.

[69] L. Zhang, H.B. Wu, X.W. Lou, Adv. Energy Mater., 4 (2014) 1300958.

[70] Z. Wang, D. Luan, S. Madhavi, C. Ming Li, X. Wen Lou, Chem. Commun., 47 (2011) 8061-8063.

[71] J. Hu, J. Zheng, L. Tian, Y. Duan, L. Lin, S. Cui, H. Peng, T. Liu, H. Guo, X. Wang, F. Pan, Chem. Commun., 51 (2015) 7855-7858.

[72] S. Bae, H. Kim, Y. Lee, X. Xu, J.-S. Park, Y. Zheng, J. Balakrishnan, T. Lei, H. Ri Kim, Y.I. Song, Y.-J. Kim, K.S. Kim, B. Ozyilmaz, J.-H. Ahn, B.H. Hong, S. lijima, Nat. Nano., 5 (2010) 574-578.

[73] A.K. Geim, K.S. Novoselov, Nat. Mater., 6 (2007) 183-191.

[74] B.J. Landi, M.J. Ganter, C.D. Cress, R.A. DiLeo, R.P. Raffaelle, Energy Environ. Sci., 2 (2009) 638-654. 
[75] S.D. Perera, B. Patel, N. Nijem, K. Roodenko, O. Seitz, J.P. Ferraris, Y.J. Chabal, K.J. Balkus, Adv. Energy Mater., 1 (2011) 936-945.

[76] S. Luo, K. Wang, J. Wang, K. Jiang, Q. Li, S. Fan, Adv. Mater., 24 (2012) 2294-2298.

[77] S.Y. Chew, S.H. Ng, J. Wang, P. Novák, F. Krumeich, S.L. Chou, J. Chen, H.K. Liu, Carbon, 47 (2009) 2976-2983.

[78] C. Ban, Z. li, Z. Wu, M.J. Kirkham, L. Chen, Y.S. Jung, E.A. Payzant, Y. Yan, M.S. Whittingham, A.C. Dillon, Adv. Energy Mater., 1 (2011) 58-62.

[79] X. Li, F. Kang, W. Shen, Electrochem. Solid-State Lett., 9 (2006) A126-A129.

[80] S.W. Lee, N. Yabuuchi, B.M. Gallant, S. Chen, B.-S. Kim, P.T. Hammond, Y. Shao-Horn, Nat. Nano., 5 (2010) 531-537.

[81] H. Ma, F. Cheng, J.Y. Chen, J.Z. Zhao, C.S. Li, Z.L. Tao, J. Liang, Adv. Mater., 19 (2007) 4067-4070.

[82] A. Magasinski, P. Dixon, B. Hertzberg, A. Kvit, J. Ayala, G. Yushin, Nat. Mater., 9 (2010) 353-358.

[83] D. Mazouzi, B. Lestriez, L. Roué, D. Guyomard, Electrochem. Solid State Lett., 12 (2009) A215-A218.

[84] C.K. Chan, R.N. Patel, M.J. O'Connell, B.A. Korgel, Y. Cui, ACS Nano, 4 (2010) 1443-1450. 
[85] L. Shen, E. Uchaker, C. Yuan, P. Nie, M. Zhang, X. Zhang, G. Cao, ACS Appl. Mater. Interfaces, 4 (2012) 2985-2992.

[86] M. Gaberscek, R. Dominko, J. Jamnik, Electrochem. Commun., 9 (2007) 2778-2783.

[87] A.N. Jansen, D.W. Dees, D.P. Abraham, K. Amine, G.L. Henriksen, J. Power Sources, 174 (2007) 373-379.

[88] P. He, X. Zhang, Y.G. Wang, L. Cheng, Y.Y. Xia, J. Electrochem. Soc., 155 (2008) A144-A150.

[89] K. Zhang, J.-T. Lee, P. Li, B. Kang, J.H. Kim, G.-R. Yi, J.H. Park, Nano Lett., 15 (2015) 6756-6763.

[90] D. Lepage, C. Michot, G. Liang, M. Gauthier, S.B. Schougaard, Angew. Chem. Int. Ed, 50 (2011) 6884-6887.

[91] C. Hu, H. Yi, H. Fang, B. Yang, Y. Yao, W. Ma, Y. Dai, Mater. Lett., 65 (2011) 1323-1326.

[92] B. Kang, G. Ceder, Nature, 458 (2009) 190-193.

[93] H. Li, H. Zhou, Chem. Commun., 48 (2012) 1201-1217.

[94] I.A. Shkrob, A.J. Kropf, T.W. Marin, Y. Li, O.G. Poluektov, J. Niklas, D.P. Abraham, J. Phys. Chem. C, 118 (2014) 24335-24348.

[95] N. Kumagai, S. Komaba, Y. Kataoka, M. Koyanagi, Chem. Lett., 29 (2000) 1154-1155. 
[96] Y.-M. Lin, H.-C. Wu, Y.-C. Yen, Z.-Z. Guo, M.-H. Yang, H.-M. Chen, H.-S. Sheu, N.-L. Wu, J. Electrochem. Soc., 152 (2005) A1526-A1532.

[97] J.-S. Kim, C.S. Johnson, J.T. Vaughey, S.A. Hackney, K.A. Walz, W.A. Zeltner, M.A. Anderson, M.M. Thackeray, J. Electrochem. Soc., 151 (2004) A1755-A1761.

[98] J. Lu, C. Zhan, T. Wu, J. Wen, Y. Lei, A.J. Kropf, H. Wu, D.J. Miller, J.W. Elam, Y.-K. Sun, X. Qiu, K. Amine, Nat. Commun., 5 (2014).

[99] J. Yao, C. Shen, P. Zhang, D. Gregory, L. Wang, lonics, 19 (2013) 739-745.

[100] Y. Liu, J. Lv, Y. Fei, X. Huo, Y. Zhu, Ionics, 19 (2013) 1241-1246.

[101] S. Komaba, T. Itabashi, T. Ohtsuka, H. Groult, N. Kumagai, B. Kaplan, H. Yashiro, J. Electrochem. Soc., 152 (2005) A937-A946.

[102] C. Zhan, X. Qiu, J. Lu, K. Amine, Adv. Mater. Interfaces, 6 (2016) 1500856.

[103] R.V. Chebiam, A.M. Kannan, F. Prado, A. Manthiram, Electrochem. Commun., 3 (2001) 624-627.

[104] L. Liu, X. Chen, Chem. Rev., 114 (2014) 9890-9918.

[105] Z. Chen, Y. Qin, K. Amine, Y.K. Sun, J. Mater. Chem., 20 (2010) 7606-7612.

[106] J. Cho, Y.W. Kim, B. Kim, J.G. Lee, B. Park, Angew. Chem. Int. Ed, 42 (2003) 1618-1621. 
[107] Z. Chen, J.R. Dahn, Electrochim. Acta, 49 (2004) 1079-1090.

[108] X. Meng, X.-Q. Yang, X. Sun, Adv. Mater., 24 (2012) 3589-3615.

[109] Z. Wu, S. Ji, T. Liu, Y. Duan, S. Xiao, Y. Lin, K. Xu, F. Pan, Nano Lett., (2016).

[110] Y. Su, S. Cui, Z. Zhuo, W. Yang, X. Wang, F. Pan, ACS Appl. Mater. Interfaces, 7 (2015) 25105-25112.

[111] K.-S. Park, P. Xiao, S.-Y. Kim, A. Dylla, Y.-M. Choi, G. Henkelman, K.J. Stevenson, J.B. Goodenough, Chem. Mater., 24 (2012) 3212-3218.

[112] Z. Wu, S. Ji, Z. Hu, J. Zheng, S. Xiao, Y. Lin, K. Xu, K. Amine, F. Pan, ACS Appl. Mater. Interfaces, 8 (2016) 15361-15368.

[113] Z. Wu, S. Ji, J. Zheng, Z. Hu, S. Xiao, Y. Wei, Z. Zhuo, Y. Lin, W. Yang, K. Xu, K. Amine, F. Pan, Nano Lett., 15 (2015) 5590-5596.

[114] J. Lee, A. Urban, X. Li, D. Su, G. Hautier, G. Ceder, Science, 343 (2014) $519-522$.

[115] H. Guo, X. Song, Z. Zhuo, J. Hu, T. Liu, Y. Duan, J. Zheng, Z. Chen, W. Yang, K. Amine, F. Pan, Nano Lett., 16 (2016) 601-608.

[116] A. Urban, J. Lee, G. Ceder, Adv. Energy Mater., 4 (2014) 1400478.

[117] J. Hu, Y. Jiang, S. Cui, Y. Duan, T. Liu, H. Guo, L. Lin, Y. Lin, J. Zheng, K. Amine, F. Pan, Adv. Energy Mater., 6 (2016) 1600856.

[118] K. Sun, T.-S. Wei, B.Y. Ahn, J.Y. Seo, S.J. Dillon, J.A. Lewis, Adv. Mater., 25 (2013) 4539-4543. 
[119] J. Yang, J. Zheng, X. Kang, G. Teng, L. Hu, R. Tan, K. Wang, X. Song, M. Xu, S. Mu, Nano Energy, 20 (2016) 117-125.

[120] L. Wang, F. Zhou, Y.S. Meng, G. Ceder, Phys. Rev. B, 76 (2007) 165435.

[121] P. Gibot, M. Casas-Cabanas, L. Laffont, S. Levasseur, P. Carlach, S. Hamelet, J.-M. Tarascon, C. Masquelier, Nat. Mater., 7 (2008) 741-747.

[122] G. Xu, Z. Liu, C. Zhang, G. Cui, L. Chen, J. Mater. Chem. A, 3 (2015) 4092-4123.

[123] S.M. Oh, S.T. Myung, J.B. Park, B. Scrosati, K. Amine, Y.K. Sun, Angew. Chem. Int. Ed, 51 (2012) 1853-1856.

[124] L.-H. Hu, F.-Y. Wu, C.-T. Lin, A.N. Khlobystov, L.-J. Li, Nat. Commun., 4 (2013) 1687. 


\section{Table and Figures}

Table 1. Comparison of the performance of reported $\mathrm{LiFePO}_{4} \mathrm{LIBs}$ after depolarization by different methods. $\left(1 \mathrm{C}=170 \mathrm{~mA} \mathrm{~g}^{-1}\right)$.

\begin{tabular}{|c|c|c|c|c|}
\hline $\begin{array}{c}\text { Depolarization } \\
\text { methods }\end{array}$ & & $\begin{array}{c}\text { Particle } \\
\text { size }\end{array}$ & $\begin{array}{l}\text { Discharge } \\
\text { rates }(\mathrm{C})\end{array}$ & $\begin{array}{c}\text { Discharge capacity } \\
(\mathrm{mAh} / \mathrm{g})\end{array}$ \\
\hline Metal doing in bulk & undoped & & $1 / 30$ & 22 \\
\hline 12 wt.\% carbon & & $50 \sim 20 \mathrm{~nm}$ & & \\
\hline Ref. 4 & doped $\left(\mathrm{Zr}^{4+}\right)$ & & 19 & 65 \\
\hline Nanostructure design & (100) exposure facet & $200 \mathrm{~nm} \times$ & 10 & 28 \\
\hline 10 wt. $\%$ carbon & & $150 \mathrm{~nm} \times$ & & \\
\hline Ref. 13 & (010) exposure facet & $30 \mathrm{~nm}$ & 10 & 148 \\
\hline Surface coating with a fast & uncoated & & 200 & 80 \\
\hline ion-conducting layer & & $50 \mathrm{~nm}$ & & \\
\hline $65 \mathrm{wt} \%$ carbon (Ref. 92) & coated & & 200,400 & 100,60 \\
\hline Surface doping & undoped & & 10 & ح20 \\
\hline 17 wt. $\%$ carbon & & $100 \sim 500$ & & $\approx 22$ \\
\hline \multirow[t]{2}{*}{ Ref. 111} & doped $(S)$ & $\mathrm{nm}$ & 10 & \\
\hline & & & & 86.4 \\
\hline Electrode/electrolyte & Organic electrolyte & & 200 & 20 \\
\hline interface, 50 wt. $\%$ carbon & & $45 \mathrm{~nm}$ & & \\
\hline Ref. 21 & Aqueous electrolyte & & 600 & 72 \\
\hline
\end{tabular}


(a)

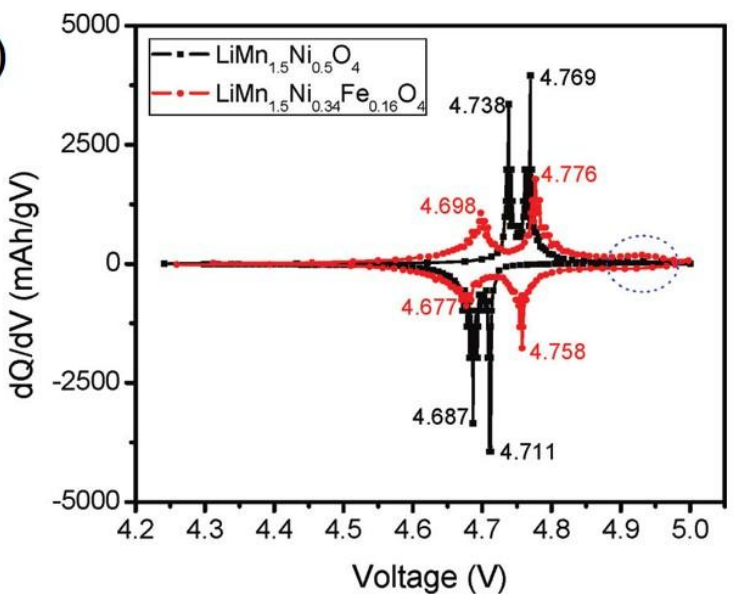

(c)

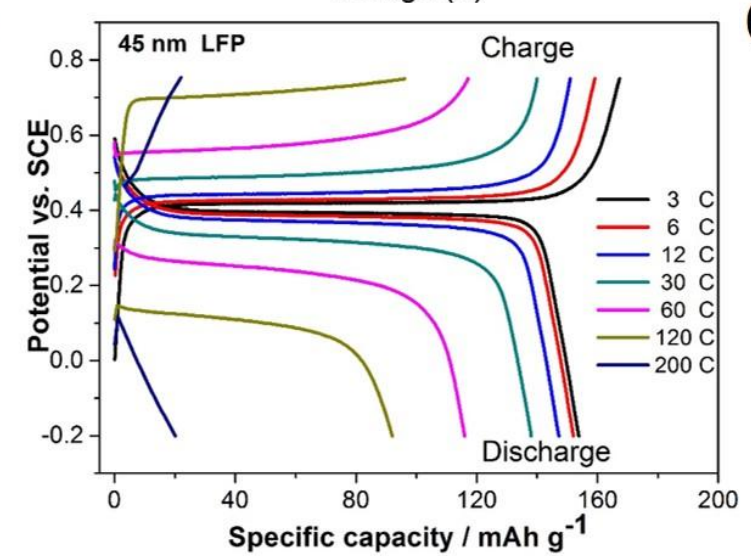

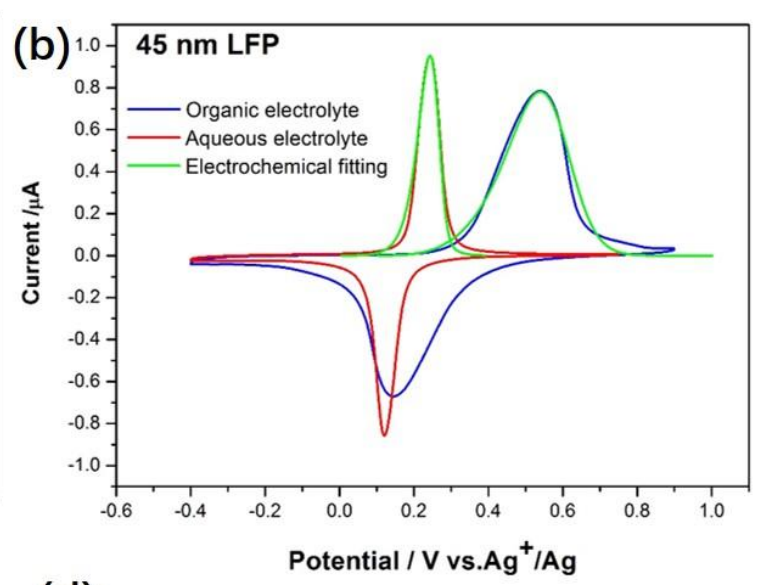

(d)

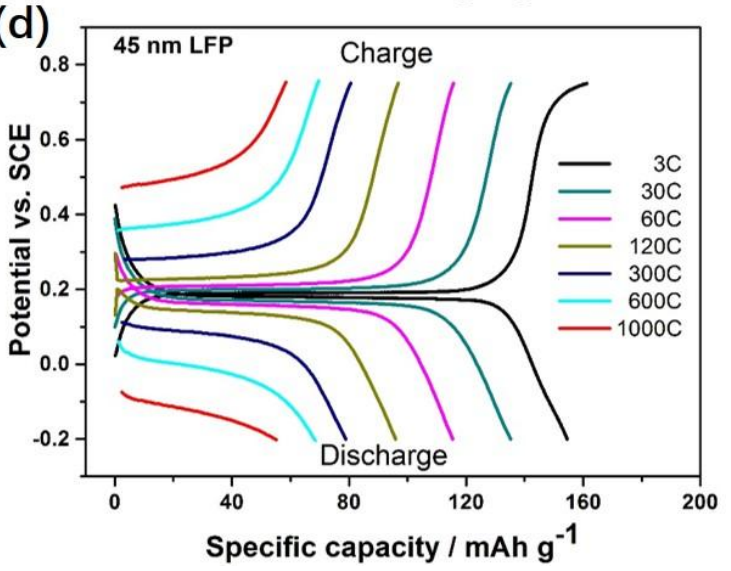

Fig. 1. Polarization effect in electrode materials. (a) $d Q / d V$ vs. voltage of $\mathrm{LiMn}_{1.5} \mathrm{Ni}_{0.5} \mathrm{O}_{4}$ and $\mathrm{LiMn}_{1.5} \mathrm{Ni}_{0.34} \mathrm{Fe}_{0.16} \mathrm{O}_{4}$. (b) Cyclic voltammograms for 45-nm $\mathrm{LiFePO}_{4}$ (LFP) nanoparticles in $0.5 \mathrm{M} \mathrm{Li}_{2} \mathrm{SO}_{4}$ aqueous electrolyte and in $1 \mathrm{~mol} \mathrm{~L}^{-1}$ $\mathrm{LiClO}_{4}$ organic electrolyte (a mixture of ethylene carbonate and dimethyl carbonate) at scan rate of $20 \mathrm{mV} \mathrm{s}^{-1}$. A Pt wire is used as the counter electrode and $\mathrm{Ag} / \mathrm{AgCl}$ as the reference electrode. Note that separations between cathodic and anodic peaks in aqueous electrolyte $(\sim 0.1 \mathrm{~V})$ are much smaller than those in non-aqueous $(\sim 0.5 \mathrm{~V})$ electrolyte. (c) Same curves for an organic electrolyte $\left(1 \mathrm{M} \mathrm{LiClO}_{4}\right.$ electrolyte in a mixture of ethylene carbonate and dimethyl carbonate). (d) Charge and discharge 
curves at different current densities $\left(1 \mathrm{C}=170 \mathrm{~mA} \mathrm{~g}^{-1}\right)$ for cells cycled between -0.2 and $0.75 \mathrm{~V}$ (vs. SCE) in $0.5 \mathrm{M} \mathrm{Li}_{2} \mathrm{SO}_{4}$ aqueous electrolyte. Reprinted with permission from ref. 7 and 21.

(a)

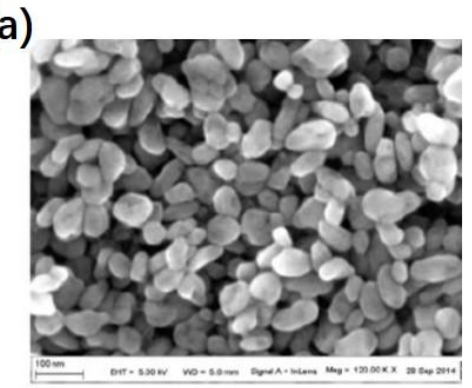

(d)

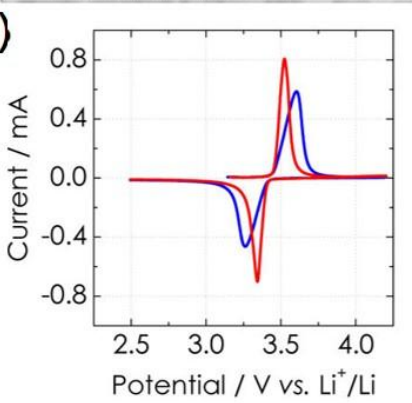

(b)

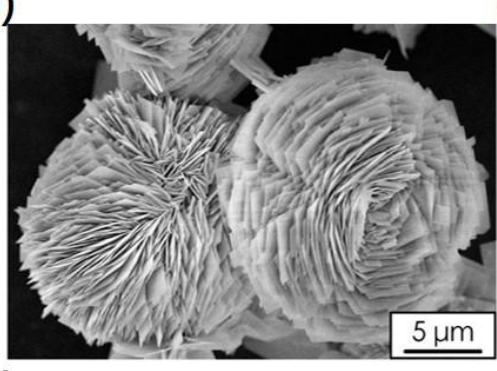

(e)

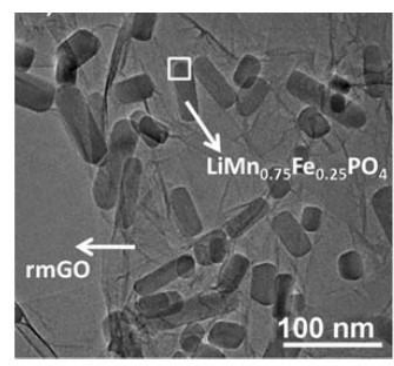

(c)

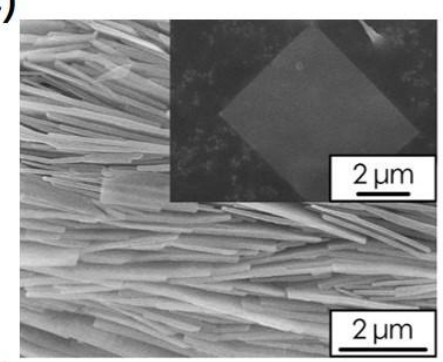

(f)

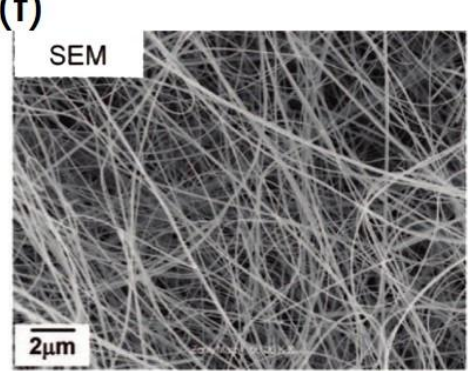

(g)

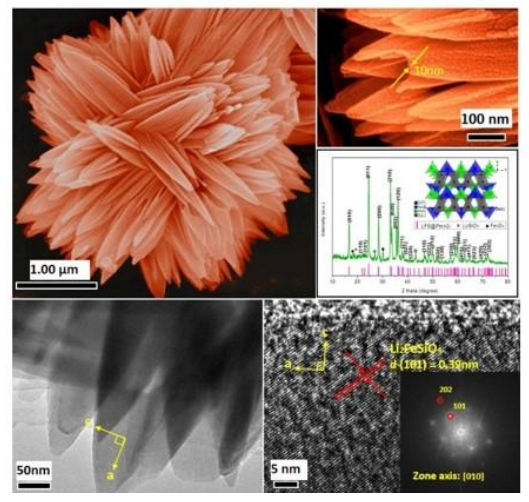

(h)

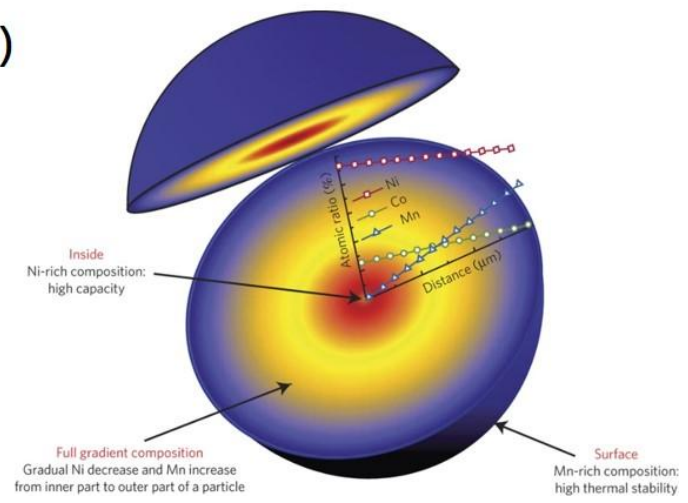

Fig. 2. Nanostructured cathode materials. (a) $\mathrm{LiFePO}_{4}$ nanoparticles, (b) and (c) $\mathrm{LiFePO}_{4}$ nanosheets, (d) Cyclic voltammetric profiles of $\mathrm{LiFePO}_{4}$ nanosheets (red) and commercial $\mathrm{LiFePO}_{4} / \mathrm{C}$ powders (blue) at a fixed scan rate of $0.1 \mathrm{mV} \mathrm{s}^{-1}$. (e) $\mathrm{LiMn}_{0.25} \mathrm{Fe}_{0.75} \mathrm{PO}_{4}$ nanorods, (f) $\mathrm{LiMn}_{2} \mathrm{O}_{4}$ nanowires, (g) d-hierarchical flower-like 
$\mathrm{Li}_{2} \mathrm{FeSiO}_{4}$ with secondary nanopetals, and (h) full-concentration gradient cathodes with the concentration of nickel continuously decreasing from the center to the surface. Reprinted with permission from ref. 21, 28, 30, 33, 36, and 39.

(a)

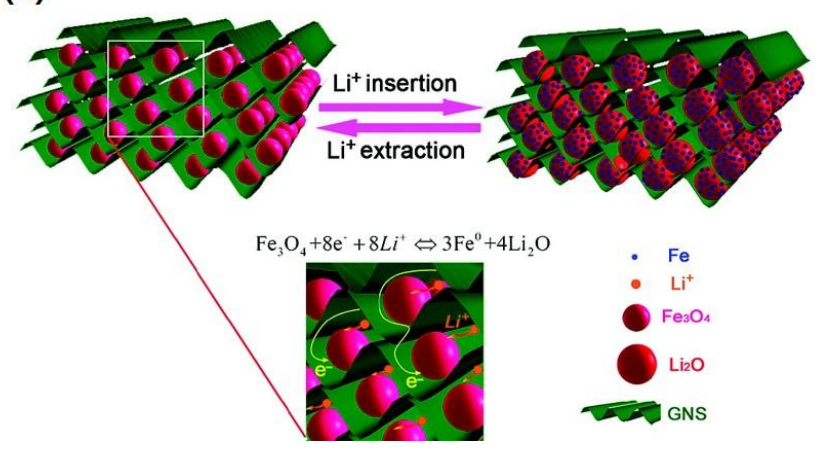

(b)

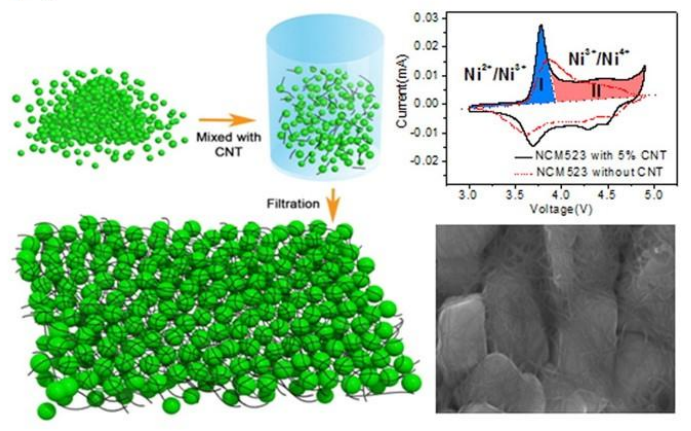

Fig. 3. Nanocomposite electrode materials. (a) Schematic of a flexible interleaved structure consisting of graphene nanosheets and $\mathrm{Fe}_{3} \mathrm{O}_{4}$ particles. (b) Schematic of bedding $\mathrm{Li}\left(\mathrm{Ni}_{0.5} \mathrm{Mn}_{0.3} \mathrm{Co}_{0.2}\right) \mathrm{O}_{2}$ in the single-wall carbon nanotube network. The well-defined two-stage delithiation kinetics in $\mathrm{Li}\left(\mathrm{Ni}_{0.5} \mathrm{Mn}_{0.3} \mathrm{Co}_{0.2}\right) \mathrm{O}_{2}$ was enabled by the depolarization and observed clearly. Reprinted with permission from ref. 19 and 11. 
(a)
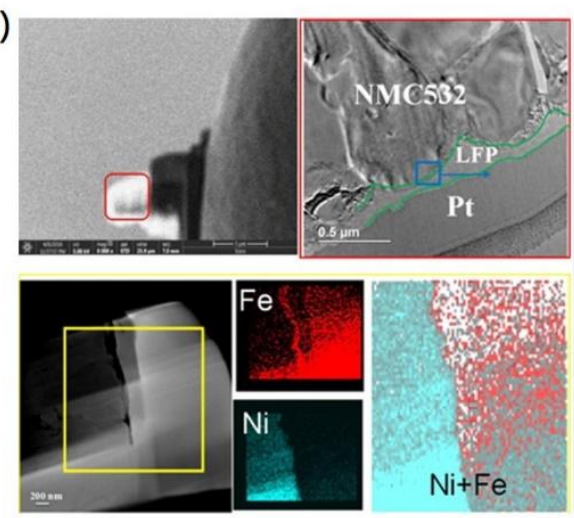

(c)

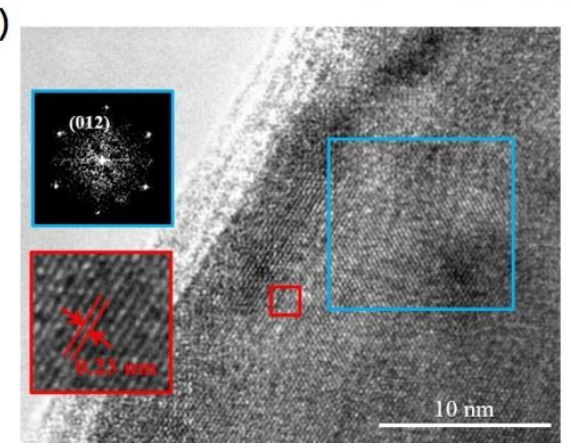

(b)

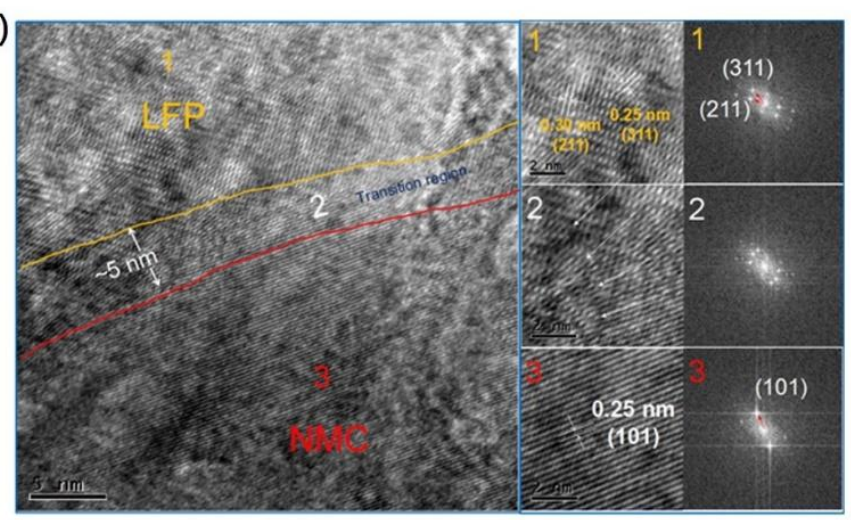

(d)

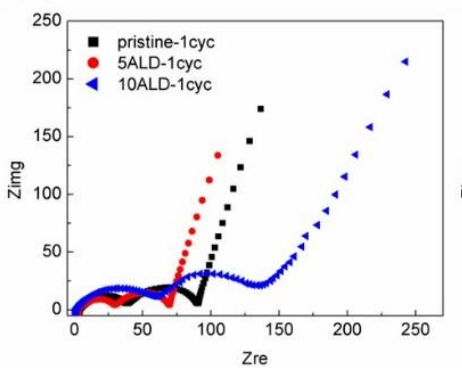

(e)

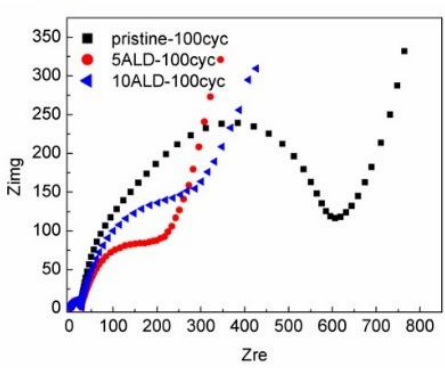

Fig. 4. Surface coating or sub-nanometer coating. (a) and (b) Coating of $\mathrm{Li}\left(\mathrm{Ni}_{0.5} \mathrm{Mn}_{0.3} \mathrm{Co}_{0.2}\right) \mathrm{O}_{2}$ particles with $\mathrm{LiFePO}_{4}$ nanoparticles. TEM image of the interface and the distributions of $\mathrm{Ni}$ and $\mathrm{Fe}$ at the interface (a). High resolution TEM image of the interface and crystal lattice and electron diffraction images of the locations marked 1, 2, and 3 (b). (c) TEM images of 10-layer ALD $\mathrm{Li}\left(\mathrm{Ni}_{0.5} \mathrm{Mn}_{0.3} \mathrm{Co}_{0.2}\right) \mathrm{O}_{2}$ electrodes. (d) and (e) Nyquist plots for different $\mathrm{Li}\left(\mathrm{Ni}_{0.5} \mathrm{Mn}_{0.3} \mathrm{Co}_{0.2}\right) \mathrm{O}_{2}$ electrodes (d) after an initial charging to $4.5 \mathrm{~V}$ at a $0.1 \mathrm{C}$ rate and (e) after charging to $4.5 \mathrm{~V}$ after 100 cycles at a $0.5 \mathrm{C}$ rate. Reprinted with permission from ref. 109 and 110. 
(a)

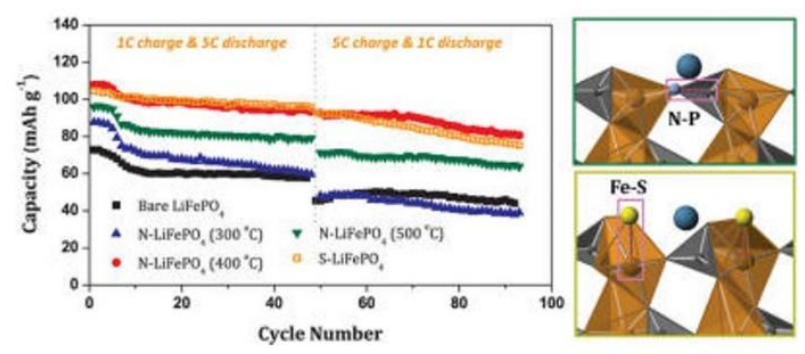

(b)

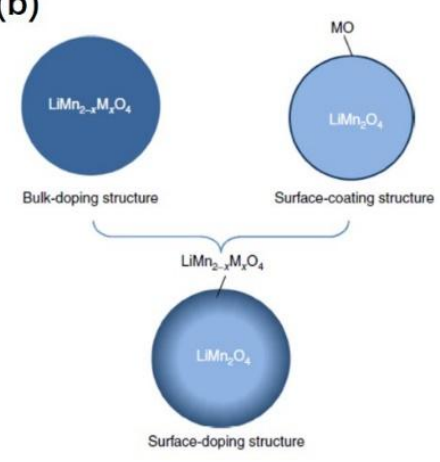

(d)

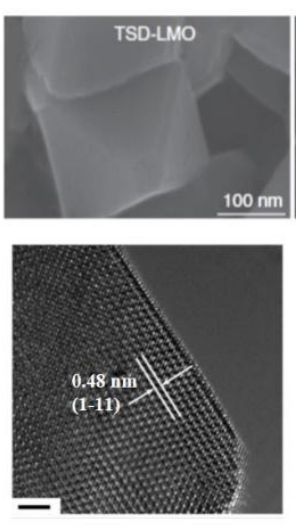

Fig. 5. (a) Surface nitrogen or sulfur doping can improve greatly the charge transfer kinetics and the charge/discharge performance of a $\mathrm{LiFePO}_{4}$ cathode. (b) The structures resulting from bulk doping, surface-coating and surface-doping (M represents the dopant cation). Scanning electron microscopy images and high-resolution TEM images of surface-doped $\mathrm{LiMn}_{2} \mathrm{O}_{4}$ particles showing uniform structure from surface to the interior. Reprinted with permission from ref. 111 and 98. 
(a)

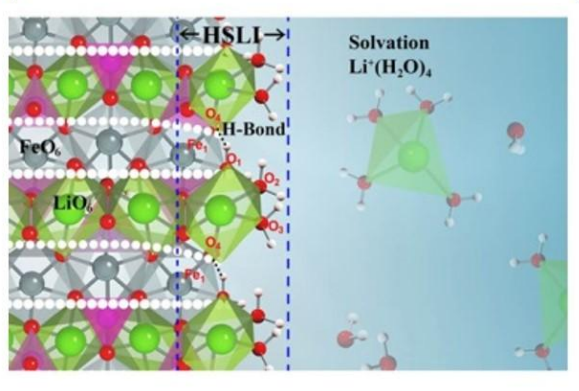

(b)

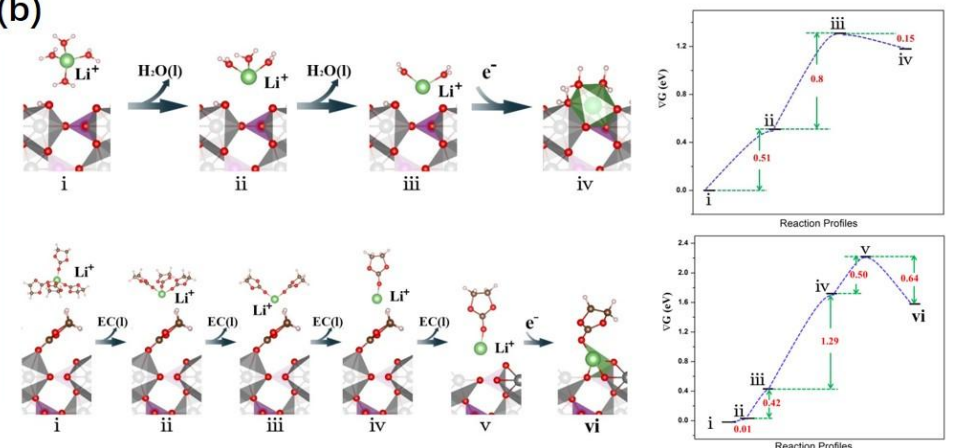

Fig. 6. (a) The novel "Janus" hydrated interface in the $\mathrm{LiFePO}_{4}-\mathrm{H}_{2} \mathrm{O}$ system. (b) The reaction profiles for $\mathrm{Li}$-ions transport across the $\mathrm{FePO}_{4} /$ water interface and $\mathrm{FePO}_{4} / \mathrm{EC}$ interface in the discharge process and their energies at each step (right hand panels). $\mathrm{Li}$, green; Fe, gray; P, purple; O, red; C, brown; H, white. Reprinted with permission from ref. 21. 
(a)

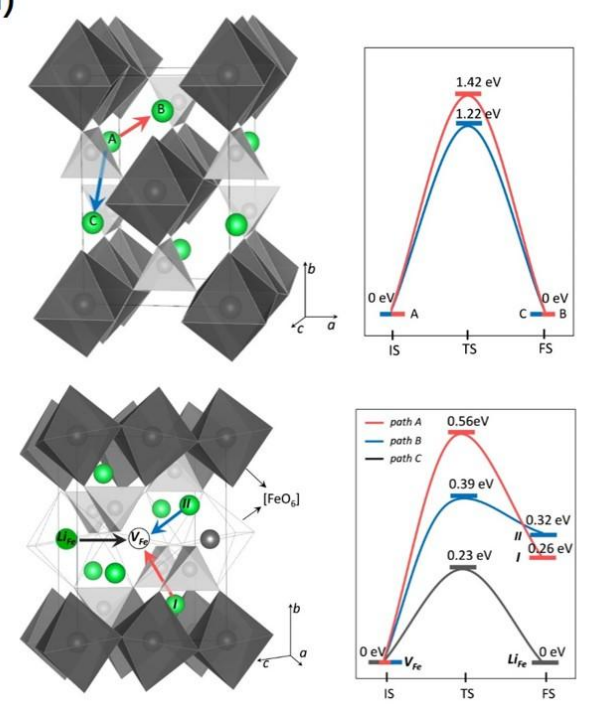

(b)

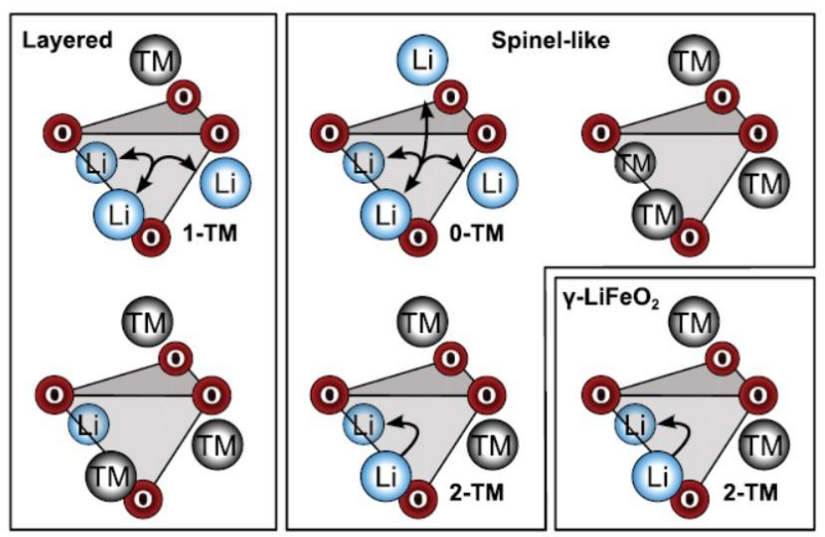

Fig. 7. (a) Disordered structures in $\beta-\mathrm{LiFePO}_{4}$. The induced disorder (such as $\mathrm{Fe}_{\mathrm{Li}} \mathrm{Li}_{\mathrm{Fe}}$ antisite defects, crystal distortion, and amorphous domains) decreases the activation barriers of Li-ion diffusion greatly and creates new lithium migration passages. (b) Cation distributions around tetrahedral sites in the stoichiometric ordered layered lithium transition-metal oxides. Potential lithium diffusion channels are indicated with arrows. Reprinted with permission from ref. 115 and 116. 
Graphic for the Table of Contents
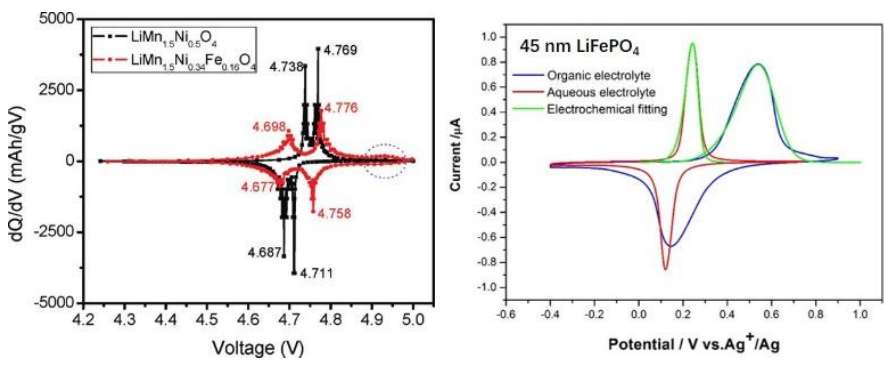


\section{Author biosketch}

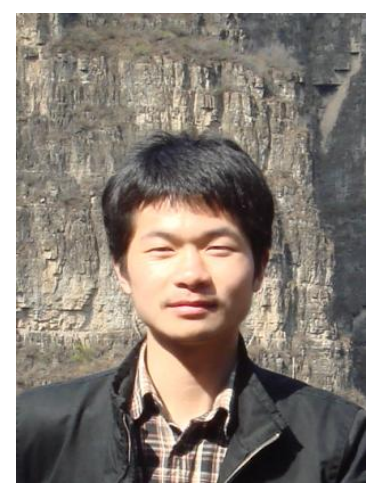

Prof. Jiaxin Zheng received his BSc in Physics in 2008 and $\mathrm{PhD}$ degree in Condensed Matter Physics in 2013 from Peking University, China. Then he joined the group of Prof. Feng Pan at School of Advanced Materials (SAM), Peking University, Shenzhen Graduate School, China, as a post-doctoral fellow from Oct. 2013 to Oct. 2015. Now he works an associate Professor at SAM. His research interests include: computational materials, energy materials (battery materials, solar energy, thermoelectric materials), nanomaterials, nanoelectronics. Dr. Zheng has authored/co-authored more than 80 peer-reviewed research articles.

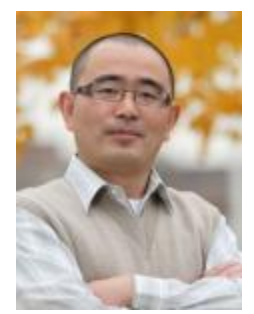

Dr. Jun Lu is a chemist at Argonne National Laboratory. His research interests focus on the electrochemical energy storage and conversion technology, with main focus on beyond Li-ion battery technology. Dr. Lu earned his bachelor degree in Chemistry Physics from University of Science and Technology of China (USTC) in 2000. He completed his Ph.D. from the Department of Metallurgical Engineering at University of Utah in 2009 with a major research on metal hydrides for reversible hydrogen storage application. He is the awardee of the first DOE-EERE postdoctoral fellow under Vehicles Technology Program from 2011-2013. Dr. Lu has authored/co-authored more than 130 peer-reviewed research articles and has filed over dozen patents and patent applications. 


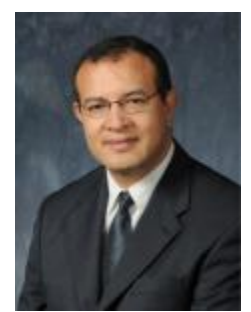

Dr. Khalil Amine is a Distinguished Fellow and the Manager of the Advanced Battery Technology programs at Argonne National Laboratory, where he is responsible for directing the research and development of advanced materials and battery systems for HEV, PHEV, EV, satellite, military and medical applications. Dr. Amine currently serves a member of the U.S. National Research Consul on battery related technologies. Among his many awards, Dr. Khalil is a 2003 recipient of Scientific America's Top Worldwide Research 50 Research Award, a 2009 recipient of the US Federal Laboratory Award for Excellence in Technology Transfer, and is the five-time recipient of the R\&D 100 Award, which is considered as the Oscar of technology and innovation. In addition, he was recently awarded the ECS battery technology award and the international battery association award. Dr. Amine holds or has filed over 130 patents and patent applications and has over 280 publications. From 1998 to 2008, Dr. Amine was the most cited scientist in the world in the field of battery technology.

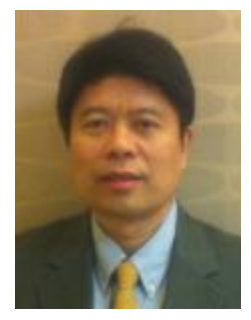

Prof. Feng Pan, founding Dean of School of Advanced Materials, Peking University Shenzhen Graduate School, got B. S. from Dept. Chemistry, Peking University in 1985 and Ph.D. from Dept. of P\&A Chemistry, University of Strathclyde, Glasgow, UK, with "Patrick D. Ritchie Prize" for the best pH. D. in 1994. With more than a decade experience in large international incorporations, Prof. Pan has been engaged in fundamental research and product development of novel optoelectronic and energy storage materials and devices. As Chief Scientist, Prof. Pan led eight entities in Shenzhen to win the 150 million RMB grant for the national new energy vehicles (power battery) innovation project since 2013. 


\section{Graphical Abstract}
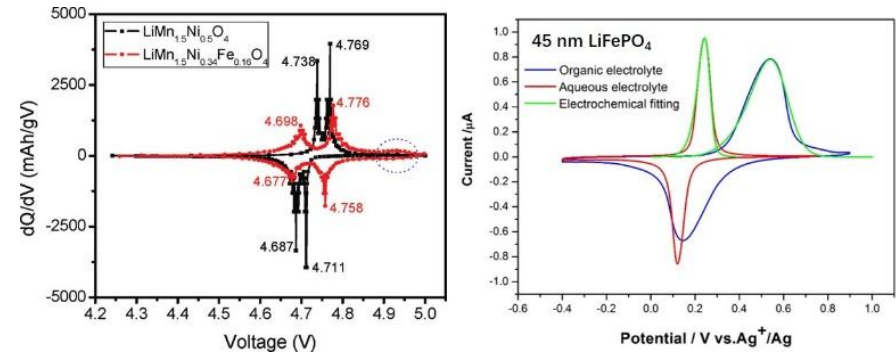

The polarization effect and depolarization effect in electrode materials: $\mathrm{LiMn}_{1.5} \mathrm{Ni}_{0.5} \mathrm{O}_{4}$ (left) and $\mathrm{LiFePO}_{4}$ (right). Before depolarization effect, a large difference in potential between the anodic and cathodic peaks can be observed (polarization). After Fe doping in $\mathrm{LiMn}_{1.5} \mathrm{Ni}_{0.5} \mathrm{O}_{4}$ and cycling in aqueous electrolyte for $\mathrm{LiFePO}_{4}$, the differences in potential between the anodic and cathodic peaks are greatly reduced (depolarization effect). 